\title{
CAMBIOS EN EL COMERCIO EXTERIOR DE LOS PAÍSES DEL ESTE. LA DIFÍCIL REINSERCIÓN EN EUROPA
}

\author{
POR \\ RAFAEL VIRUELA MARTÍNEZ
}

Las fuentes de información

Antes de pasar a comentar la evolución y composición del comercio de los países del Este, resulta interesante una breve referencia a las fuentes de información. La apertura económica de la región tras la caída del comunismo ha proporcionado abundante material a los estudiosos de la transición. Buena parte de las obras que se citan en la bibliografía tienen carácter complementario, bien porque se refieren a un solo país o región. La actividad comercial, pese a sus implicaciones geográficas, no ha atraído la atención de los geógrafos. La mayor parte de los autores son economistas: Andreff, Labaronne, Lavigne o Tiraspolsky y, entre los españoles, Luengo, Lobejón, Palazuelos, etc.

Los trabajos de estos últimos se han venido publicando en la revista Cuadernos del Este y en los informes anuales del Instituto de Estudios de Europa Oriental, donde se analiza el alcance de las reformas económicas y las causas y consecuencias de la desintegración económica del bloque del Este. Asimismo hay que destacar los artículos aparecidos en el Boletín Económico del ICE y en Información Comercial Española, revista que ha dedicado varios números monográficos a la transformación de Europa central y oriental: «Reforma y apertura de las economías del Este» (núm. 674, 1989), «La transición económica en Europa Central

Rafael Viruela Martínez. Departamento de Geografía. Universidad de Valencia.

Estudios Geográficos

Tomo LX, n. ${ }^{\circ} 237$, octubre-diciembre 1999 
y del Este» (núm. 717, 1993) o «Apertura económica en Europa: el Este mira hacia el Oeste» (núm. 738, 1995). Son muy interesantes los trabajos publicados en la Revue d'Études Comparatives Est-Ouest y muy especialmente en Le Courrier des Pays de l'Est, con artículos sobre la reorientación geográfica de los flujos y los problemas a que se enfrentan los países de la región en su objetivo por reinsertarse plenamente en la economía mundial.

Como obras básicas hemos de citar los libros de Graziani (1982), Bogomolov (1989) y Chavigny (1996). Los dos primeros, editados antes de la desaparición del CAEM, aportan información valiosísima sobre el funcionamiento de la organización, las relaciones de dominación/dependencia entre la URSS y sus socios, la especialización productiva-exportadora y las relaciones con el resto del mundo. Régis Chavigny, tras exponer la situación anterior a 1989 y las reformas económicas, explica la reciente reorientación geográfica de los flujos comerciales.

La información estadística procede de diversos organismos, con resultados muchas veces contradictorios. Hemos optado por uno u otro según los objetivos. El GATT/OMC ofrece la serie más larga y completa de exportaciones e importaciones, lo que permite analizar la evolución de los intercambios y la balanza comercial. La dirección de los flujos aparece más detallada en las publicaciones de Naciones Unidas, el Étude sur la situation économique de l'Europe y Commodity trade statistics, y el Fondo Monetario Internacional, Direction of trade statistics. Yearbook. En las estadísticas de la ONU se incluye la composición de las exportaciones e importaciones. No hemos podido disponer de la misma información para todos los países de la región. Para evitar lagunas se ha recurrido a EconPlan y estadísticas publicadas en alguno de sus artículos citados.

Los resultados aportados por los diferentes organismos se basan en la información nacional o, cuando no es posible, en estimaciones propias. En este sentido, destaca la gran disparidad de los resultados a la que ya se han referido varios autores (Luengo, 1993; Matejka, 1994; Bayou, 1995; Tiraspolsky, 1995; etc.). Sirva como ejemplo el aportado por Céline Bayou para Polonia. Según el Banco Nacional Polaco, 1992 registró un excedente comercial de 512 millones de dólares. Sin embargo, para la Oficina Polaca de Estadística hubo un déficit de 2.700 millones. Por lo demás, las estadísticas subestiman el comercio entre los países del Este. Es tal la desconfianza entre los ex socios del CAEM que mu- 
chos países acuden a intermediarios occidentales. Buena parte del comercio entre los países de la región se realiza a través de Austria. En consecuencia, hemos de considerar la información con suma cautela y observar las tendencias más significativas.

\section{Evolución del comercio exterior de la URSS/Rusia y los Países del Este}

La geografía del comercio exterior de Europa Central y Oriental (PECO $)^{1}$ ha estado condicionada por los avatares de la política y las relaciones internacionales. A lo largo del siglo xx se pueden distinguir tres grandes etapas que pasamos a describir brevemente.

Relaciones comerciales en la primera mitad del siglo.-Tal como se puede apreciar en el cuadro I y su representación gráfica (figura 1), antes de la Segunda Guerra Mundial el comercio intrarregional era débil (no superó el $20 \%$ del comercio total). Los intercambios eran más intensos con Europa occidental, en particular con el Reino Unido y Alemania $^{2}$ debido a la proximidad geográfica y la existencia de vínculos históricos y culturales (Labaronne, 1996 a).

A excepción de Checoslovaquia, la composición de los intercambios reflejaba el menor desarrollo del Este del continente europeo (Chavigny, 1996), que exportaba alimentos, materias primas y productos semiacabados, a cambio de manufacturas, en especial bienes de equipo.

«Guerra fría» y autarquía de bloque (1949-1989).-Al término de la Segunda Guerra Mundial, la división de Europa en dos bloques política e ideológicamente enfrentados tendrá un gran impacto en el co-

\footnotetext{
1 Los países considerados en este artículo son los socios europeos del CAEM: Polonia, Hungría, ex Checoslovaquia, Bulgaria, Rumanía (PECO) y la ex URSS.

2 En 1938, Bulgaria concentraba casi el 60\% de sus exportaciones en el mercado alemán; Hungría y Yugoslavia lo hacían en más de un 40\%; Rumanía, Polonia y Checoslovaquia en un $20-30 \%$. Por el lado de las importaciones, los suministros alemanes representaban más de la mitad de las compras búlgaras, más del 40\% de las rumanas, húngaras y yugoslavas, y en torno al $20 \%$ de las polacas y checas. Desde la óptica alemana, mientras sus exportaciones mundiales se redujeron en un 40\% entre 1929 y 1937, las cuotas de venta a esos países pasaron del 4 al 10\% del total. (Palazuelos, E. (1996): Las economías postcomunistas de Europa del Este, p. 441).
} 


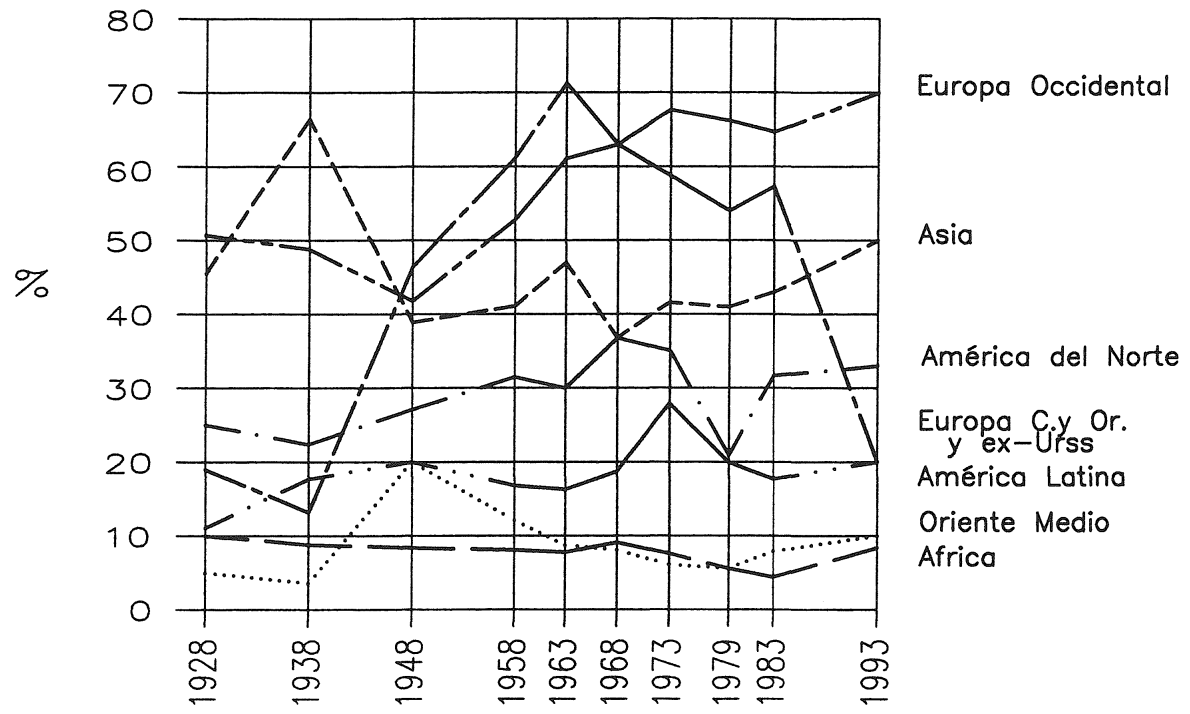

Fig. 1.-Importancia relativa del comercio intrazonal (exportaciones más importaciones) en el comercio total de varias regiones, entre 1928-1993.

Fuente: Focus, Boletín de Información de la OMC, núm. 3, mayo-junio, 1995, p. 11.

mercio exterior de los países del Este. A partir de entonces y durante el largo período de «Guerra Fría» predominan los intercambios mutuos. El comercio intrarregional aumentó rápidamente, superando el $70 \%$ del comercio total en los años 90 (cuadro I). La Unión Soviética era el socio principal de los PECO, especialmente de Bulgaria, la República Democrática Alemana y Rumanía (véase el cuadro II). En consecuencia, el comercio con otras regiones tuvo durante esta larga etapa un carácter residual o, si se prefiere, complementario. A ello contribuyó el funcionamiento del $\mathrm{CAEM}^{3}$ y el hostigamiento practicado por las potencias occidentales contra los regímenes comunistas (Palazuelos, 1996).

${ }^{3}$ El CAEM (Consejo de Ayuda Económica Mutua) se creó el 1 de enero de 1949 a iniciativa de la URSS, en respuesta al Plan Marshall de ayuda a la reconstrucción propuesta por los EEUU. Estuvo integrado por la URSS, Polonia, Checoslovaquia, Hungría, Rumanía, Bulgaria, la República Democrática Alemana (hasta 1990) y Albania, que abandonó la organización en 1961. Fuera del continente europeo eran miembros del CAEM, Mongolia, Vietnam y Cuba. La última reunión se celebró en junio de 1991 en Budapest.

$$
-696-
$$




\section{CUADRO I}

PORCENTAJE DE COMERCIO INTRARREGIONAL (EXPORTACIONES MÁS IMPORTANTES) EN EL COMERCIO TOTAL DE VARIAS REGIONES, 1928-1993

\begin{tabular}{lrrrrrrrrrrr}
\hline & $\mathbf{1 9 2 8}$ & $\mathbf{1 9 3 8}$ & $\mathbf{1 9 4 8}$ & $\mathbf{1 9 5 8}$ & $\mathbf{1 9 6 3}$ & $\mathbf{1 9 6 8}$ & $\mathbf{1 9 7 3}$ & $\mathbf{1 9 7 6}$ & $\mathbf{1 9 8 3}$ & $\mathbf{1 9 9 3}$ \\
\hline $\begin{array}{l}\text { Europa Occidental } \\
\text { Europa Central }\end{array}$ & 50,7 & 48,8 & 41,8 & 52,8 & 61,1 & 63,0 & 67,7 & 66,2 & 64,7 & 69,9 \\
y Oriental y ex URSS & $\mathbf{1 9 , 0}$ & $\mathbf{1 3 , 2}$ & $\mathbf{4 6 , 4}$ & $\mathbf{6 1 , 2}$ & $\mathbf{7 1 , 3}$ & $\mathbf{6 3 , 5}$ & $\mathbf{5 8 , 8}$ & $\mathbf{5 4 , 0}$ & $\mathbf{5 7 , 3}$ & $\mathbf{1 9 , 7}$ \\
América del Norte & 25,0 & 22,4 & 27,1 & 31,5 & 30,5 & 36,8 & 35,1 & 20,9 & 31,7 & 33,0 \\
América Latina & 11,1 & 17,7 & 20,0 & 16,8 & 16,3 & 18,7 & 27,9 & 20,2 & 17,7 & 19,4 \\
Asia & 45,5 & 66,4 & 38,9 & 41,1 & 47,0 & 36,6 & 41,6 & 41,0 & 43,0 & 49,7 \\
África & 10,3 & 8,8 & 8,4 & 8,1 & 7,8 & 9,1 & 7,6 & 5,6 & 4,4 & 8,4 \\
Oriente Medio & 5,0 & 3,6 & 20,3 & 12,1 & 8,7 & 8,1 & 6,1 & 6,4 & 7,9 & 9,4 \\
\hline
\end{tabular}

Fuente: Focus, Boletín de Información de la OMC, núm. 3, mayo-junio, 1995, p. 11.

El CAEM organizaba los intercambios según «la división internacional socialista del trabajo» (Graziani, 1982). Cada país estaba obligado a exportar dentro del bloque, aun en el caso de que resultase más ventajoso hacerlo en el mercado mundial. El objetivo era producir dentro del área todo lo que fuera posible (autarquía de bloque). Los socios adaptaban la estructura productiva y los intercambios a las necesidades de los otros miembros (Seurot, 1987; Luengo, 1991; Chavigny, 1992). Para ello los gobiernos se comprometían a suministrar y adquirir determinadas cantidades de mercancías. Se comerciaba con el exterior para conseguir los productos que no podían obtenerse en la región y, de esta forma, evitar estrangulamientos productivos. La decisión de importar entraña la necesidad de exportar para compensar la balanza comercial.

Por su parte, Occidente ha mantenido hasta fecha reciente una política restrictiva en el comercio con los países comunistas, sobre todo en lo referente al intercambio de determinadas mercancías. Desde 1949 el $\mathrm{COCOM}^{4}$ limitaba las exportaciones de tecnología que pudieran reforzar

4 El COCOM (Comité de Controles Multilaterales a la Exportación) se creó en 1949 a iniciativa de los EEUU. y lo formaron los países de la OTAN (excepto Islandia) y Japón. Desapareció en 1993, siendo sustituido por otro organismo de nombre muy significativo, «el Nuevo Foro», en el que participan activamente Rusia y Europa Central. En la actualidad esta institución impone restricciones y controles a las relaciones económicas con Irán, Irak, Libia y Corea del Norte.

$$
-697-
$$




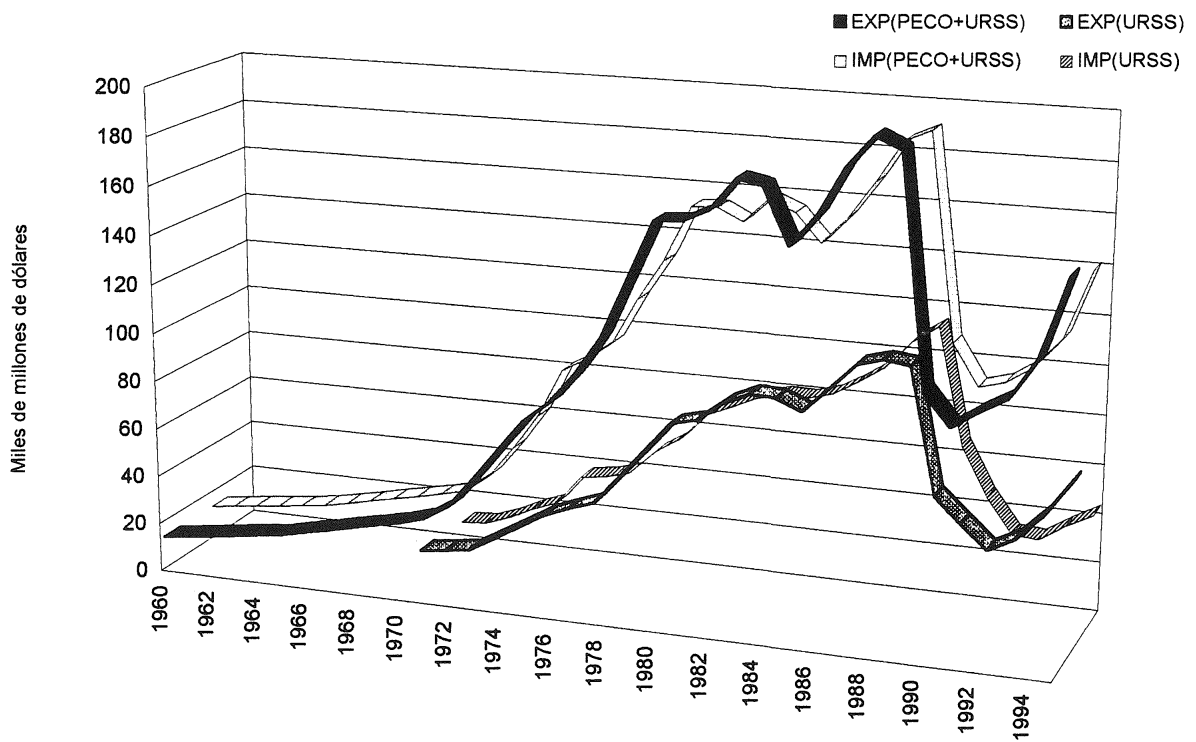

FIG. 2.-Evolución de las exportaciones e importaciones de PECO y URSS.

Fuente: GATT/OMC: El Comercio Mundial. Estadísticas, Ginebra, varios años.

el potencial militar de los países comunistas. Periódicamente se publicaba una lista de los artículos vetados: equipos electrónicos, material informático, telecomunicaciones, etc. La lista se ampliaba o reducía dependiendo del momento por el que atravesaban las relaciones entre el Este y el Oeste ${ }^{5}$. Igualmente, desde 1949 en EE.UU. la Export Control Act reglamentaba las exportaciones hacia los países socialistas (Hekimyan, 1996). Coexistía, pues, una lista COCOM y una lista americana. Esta última incluía a la primera y la superaba ampliamente.

${ }^{5}$ En los momentos más críticos de la «Guerra Fría» Occidente incrementaba los obstáculos en el comercio con el Este. La historia de las últimas décadas está jalonada de muchos ejemplos al respecto. En 1980 el presidente Carter decidió el embargo de las ventas de cereales a la URSS como represalia por la invasión de Afganistán. En 1981 Reagan impidió la exportación de material para la construcción del gasoducto eurosiberiano porque el gobierno polaco (Jaruzelski) impuso la ley marcial. En 1983 las relaciones comerciales se vieron afectadas cuando un caza soviético abatió a un boeing surcoreano. En 1989 la Comunidad Económica Europea rompió las relaciones económicas con Rumanía por considerar que no se respetaban los derechos humanos en aquel país. 
Pese a todo, las relaciones con otras regiones se incrementaron a finales de los años 1960 y durante los 1970 . Puede verse en el cuadro I la reducción porcentual del comercio interregional en unos momentos en que (figura 2) las exportaciones e importaciones se incrementaron de forma significativa. Estos años han sido calificados como la «edad de oro» del comercio Este-Oeste (Lavigne, 1985), lo que se relaciona con el clima de distensión que fue ratificado en la Conferencia sobre Seguridad y Cooperación celebrada en Helsinki en 1975 y con la necesidad que tenían los países del Este en modernizar su estructura productiva. La autosuficiencia no logró eliminar la brecha tecnológica entre el Este y el Oeste. Las importaciones de bienes de equipos occidentales, masivas en el caso de la Unión Soviética (Brand, 1982), podían financiarse con la venta de combustibles. En realidad, el comercio Este-Oeste beneficiaba a ambas partes. Occidente ofrecía cooperación científico-técnica a los países del Este. Por su parte, los países capitalistas obtenían combustibles y materias primas economizando costes de transporte por la proximidad geográfica de las nuevas áreas de aprovisionamiento.

La reciente distribución geográfica de los intercambios.-Desaparecida la servidumbre impuesta por el CAEM y debilitados los vínculos con la URSS, los flujos comerciales han experimentado una drástica readaptación geográfica (cuadro II y figura 3). Los intercambios mutuos registran una intensa y rápida contracción. En el momento actual el comercio intrazonal apenas representa el 19\% del total, cuando hace sólo diez años superaba al que se mantenía con el resto del mundo. Los países desarrollados se han convertido en los socios mayoritarios de Rusia y los PECO.

El cambio en las relaciones exteriores revela diferentes gradaciones (véase el cuadro II). Polonia y Hungría efectúan más del $70 \%$ de su comercio con los países industrializados, al igual que Chequia si no se considera el comercio con Eslovaquia. La república más pobre de la extinta Checoslovaquia tiene a su vecina como primer cliente y proveedor. Hacia los mercados occidentales también se canaliza en torno al 70\% del comercio ruso. Rumanía, país modestamente vinculado a sus antiguos socios, manifiesta una clara vocación tercermundista. Por último Bulgaria, que hasta hace muy pocos años efectuaba el $50 \%$ de sus transacciones con la URSS, sigue teniendo a su poderoso vecino como principal interlocutor. 
IMPORTACIONES URSS (\%)

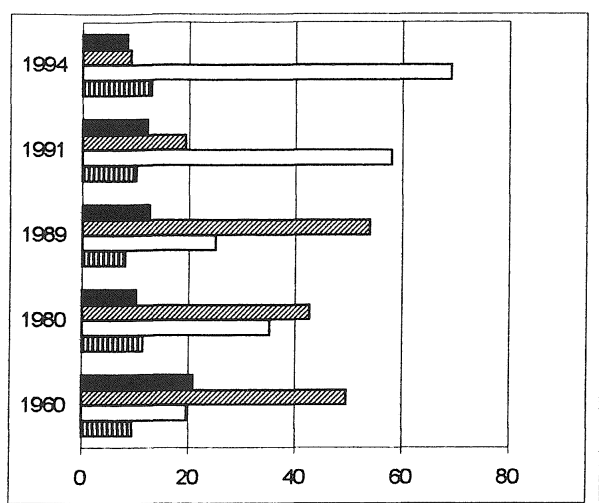

EXPORTACIONES URSS (\%)

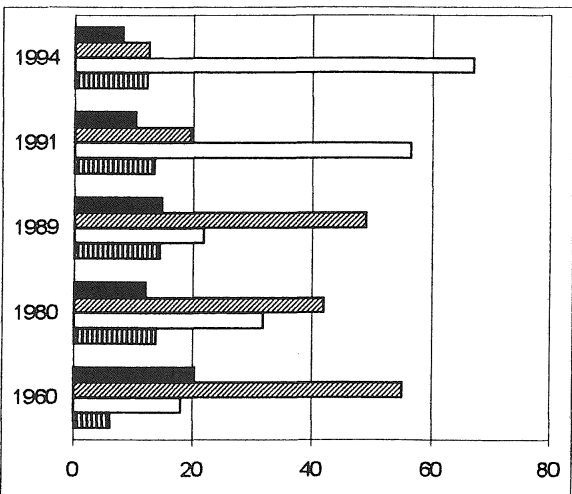

IMPORTACIONES EUROPA DEL ESTE (\%)

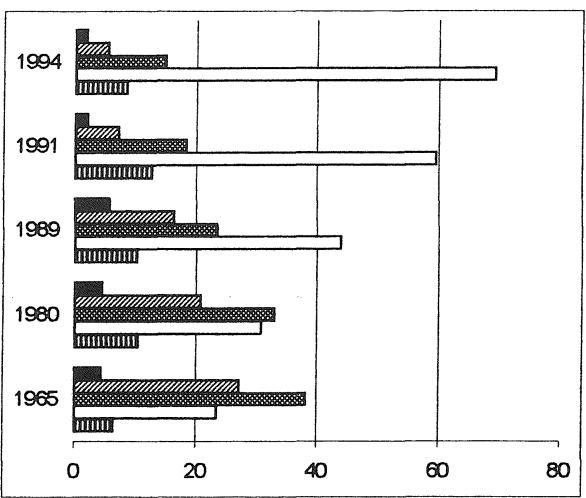

EXPORTACIONES EUROPA DEL ESTE (\%)

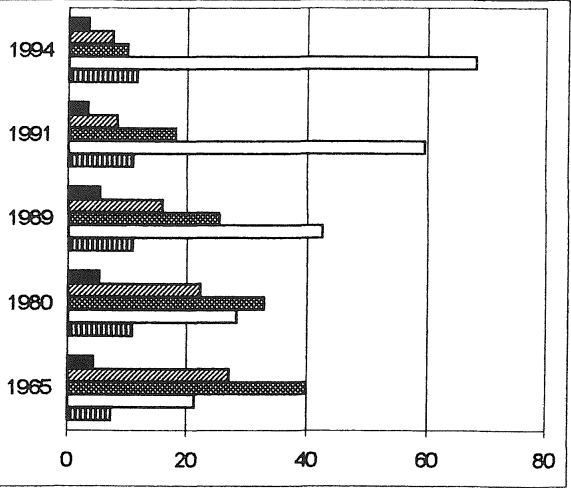

FIG. 3.-Distribución geográfica del comercio exterior por grandes grupos de paises (\%).

FUENTE: CEE/UE: Étude sur la situation économique de l'Europe, varios años; para 1960, Graziani (1982). 
CUADro II

DISTRIBUCIÓN GEOGRÁFICA DEL COMERCIO POR GRANDES GRUPOS DE PAÍSES (\%)

\begin{tabular}{|c|c|c|c|c|c|c|c|c|}
\hline & \multicolumn{4}{|c|}{ Exportaciones } & \multicolumn{4}{|c|}{ Importaciones } \\
\hline & URSS & PECO & PD & PVD & URSS & PECO & $\mathbf{P D}$ & PVD \\
\hline \multicolumn{9}{|c|}{ Hungría } \\
\hline 1960 & 29,1 & 32,2 & 21,9 & 6,6 & 29,8 & 33,0 & 24,7 & 4,4 \\
\hline 1980 & 29,3 & 21,0 & 34,0 & 10,9 & 27,7 & 19,2 & 39,5 & 9,9 \\
\hline 1989 & 25,1 & 16,9 & 43,1 & 9,5 & 22,1 & 17,1 & 49,3 & 6,3 \\
\hline 1991 & 13,4 & 5,8 & 66,8 & 9,6 & 16,3 & 6,9 & 67,8 & 8,2 \\
\hline 1994 & 10,8 & 7,4 & 71,6 & 10,1 & 14,7 & 7,1 & 70,2 & 7,1 \\
\hline \multicolumn{9}{|c|}{ Polonia } \\
\hline 1960 & 29,4 & 25,2 & 29,8 & 7,5 & 31,1 & 26,8 & 29,7 & 6,8 \\
\hline 1980 & 31,2 & 21,1 & 34,4 & 9,7 & 33,2 & 19,6 & 35,0 & 9,4 \\
\hline 1989 & 24,5 & 16,4 & 43,2 & 8,0 & 21,4 & 16,6 & 46,5 & 6,0 \\
\hline 1991 & 11,0 & 5,8 & 73,7 & 7,7 & 14,1 & 4,9 & 68,0 & 10,4 \\
\hline 1994 & 8,3 & 4,9 & 74,3 & 10,1 & 8,8 & 4,2 & 73,1 & 10,8 \\
\hline \multicolumn{9}{|c|}{ Checoslovaquia } \\
\hline 1960 & 34,1 & 29,1 & 16,7 & 11,0 & 34,7 & 28,8 & 18,9 & 9,8 \\
\hline 1980 & 35,6 & 27,8 & 21,8 & 8,6 & 36,0 & 28,7 & 24,3 & 5,5 \\
\hline 1989 & 26,5 & 20,1 & 37,6 & 9,7 & 25,9 & 21,9 & 37,6 & 8,0 \\
\hline 1991 & 19,6 & 13,2 & 52,0 & 8,6 & 29,9 & 7,4 & 51,3 & 7,9 \\
\hline $1994 *$ & 6,6 & 8,6 & 71,7 & 13,0 & 11,0 & 4,9 & 75,1 & 8,6 \\
\hline \multicolumn{9}{|c|}{ Rumania } \\
\hline 1960 & 39,2 & 26,3 & 21,3 & 5,7 & 41,0 & 26,8 & 23,4 & 3,5 \\
\hline 1980 & 19,6 & 17,7 & 34,8 & 20,5 & 15,6 & 15,1 & 31,2 & 31,0 \\
\hline 1989 & 14,5 & 10,2 & 47,7 & 23,2 & 22,6 & 14,9 & 17,2 & 39,3 \\
\hline 1991 & 22,6 & 5,7 & 44,7 & 19,0 & 17,1 & 6,9 & 39,6 & 30,2 \\
\hline 1994 & 5,8 & 5,9 & 56,0 & 31,2 & 17,5 & 4,7 & 59,7 & 17,0 \\
\hline \multicolumn{9}{|l|}{ RDA } \\
\hline 1960 & 41,9 & 26,6 & 20,2 & 4,1 & 43,6 & 22,6 & 22,0 & 4,2 \\
\hline 1980 & 33,3 & 26,2 & 29,3 & 5,9 & 33,2 & 22,4 & 34,6 & 5,5 \\
\hline 1989 & 23,8 & 22,5 & 48,5 & 5,2 & 22,0 & 20,8 & 53,1 & 4,1 \\
\hline \multicolumn{9}{|c|}{ Bulgaria } \\
\hline 1960 & 53,8 & 26,4 & 12,5 & 3,5 & 52,5 & 27,5 & 13,7 & 2,4 \\
\hline 1980 & 49,9 & 16,5 & 15,8 & 13,4 & 57,3 & 18,1 & 17,2 & 3,9 \\
\hline 1989 & 49,3 & 12,0 & 19,6 & 15,8 & 34,9 & 12,0 & 35,4 & 16,4 \\
\hline 1991 & 49,8 & 5,1 & 23,3 & 17,5 & 43,2 & 5,7 & 31,9 & 16,3 \\
\hline 1992 & 25,2 & 6,3 & 37,0 & 19,7 & 28,6 & 6,0 & 44,0 & 16,2 \\
\hline
\end{tabular}




\section{CuAdro II}

DISTRIBUCIÓN GEOGRÁFICA DEL COMERCIO POR GRANDES GRUPOS DE PAÍSES (\%) (Continuación)

\begin{tabular}{|c|c|c|c|c|c|c|c|c|}
\hline & \multicolumn{4}{|c|}{ Exportaciones } & \multicolumn{4}{|c|}{ Importaciones } \\
\hline & URSS & PECO & PD & PVD & URSS & PECO & PD & PVD \\
\hline \multicolumn{9}{|l|}{ PECO } \\
\hline 1960 & 40,0 & 27,2 & 21,4 & 7,2 & 38,3 & 27,3 & 23,5 & 6,5 \\
\hline 1980 & 33,0 & 22,4 & 28,5 & 10,8 & 33,1 & 20,9 & 31,0 & 10,5 \\
\hline 1989 & 25,5 & 15,8 & 42,6 & 10,8 & 23,5 & 16,4 & 44,0 & 10,3 \\
\hline 1991 & 18,1 & 8,2 & 59,6 & 10,9 & 18,4 & 7,2 & 59,6 & 12,7 \\
\hline 1994 & 9,8 & 7,3 & 68,1 & 11,5 & 14,9 & 5,4 & 69,4 & 8,5 \\
\hline \multicolumn{9}{|c|}{ URSS/Rusia } \\
\hline 1960 & & 55,2 & 18,2 & 6,1 & & 49,7 & 19,8 & 9,5 \\
\hline 1980 & & 42,1 & 32,0 & 13,8 & & 42,9 & 35,4 & 11,5 \\
\hline 1989 & & 49,0 & 21,9 & 14,3 & & 54,0 & 25,1 & 8,2 \\
\hline 1991 & & 19,7 & 56,5 & 13,5 & & 19,4 & 58,1 & 10,3 \\
\hline $1994 * *$ & & 12,6 & 67,0 & 12,3 & & 9,2 & 69,2 & 13,1 \\
\hline
\end{tabular}

FUENTE: CEE/UN: Étude sur la situation économique de l'Europe, varios años; UN: Commodity trade statistics, 1994, excepto en el caso de Rusia; para 1960, Graziani (1982).

* Sólo la república Checa.

** Los valores de PECO también incluyen otros países.

Nota: los valores no suman 100 porque no se incluye el comercio con otros países, la mayoría socialistas.

En los mapas de las figuras 4, 5 y 6 se representa la distribución geográfica del comercio antes de la desintegración del CAEM y en el momento actual (1996). Hemos distinguido entre Europa central, Europa oriental y la URSS/Rusia por los motivos aludidos y por exigencias de la información estadística disponible. Los resultados obtenidos muestran la magnitud del cambio en las relaciones exteriores de los países postcomunistas. Hasta hace poco el mercado soviético era crucial para los PECO y al revés. Hoy todos los países del área tienen en la Unión Europea a su principal cliente y proveedor. Dentro del espacio comunitario Alemania ocupa un destacado primer puesto, a lo que ha contribuido en parte la reunificación entre la RFA y la RDA, ya que más de la mitad del comercio de los cinco nuevos Länder se realiza con sus antiguos socios CAEM. Por lo demás, la producción alemana de maquinaria, equipamiento electrónico o automóvil responde a las necesidades de consumo de las economías en transición. 

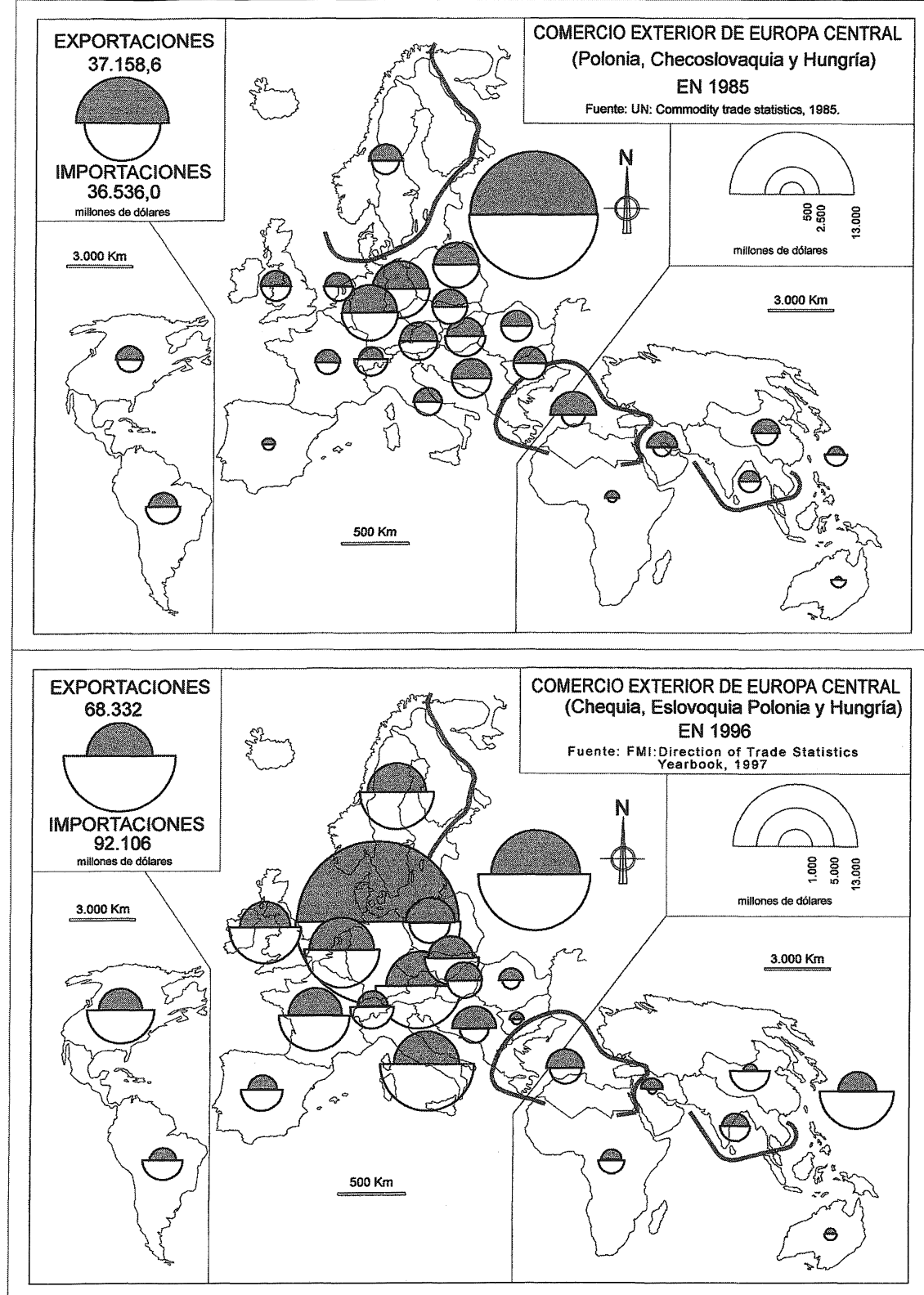

FIG. 4.-Geografía del comercio exterior de Europa central, en 1985 y 1996. 


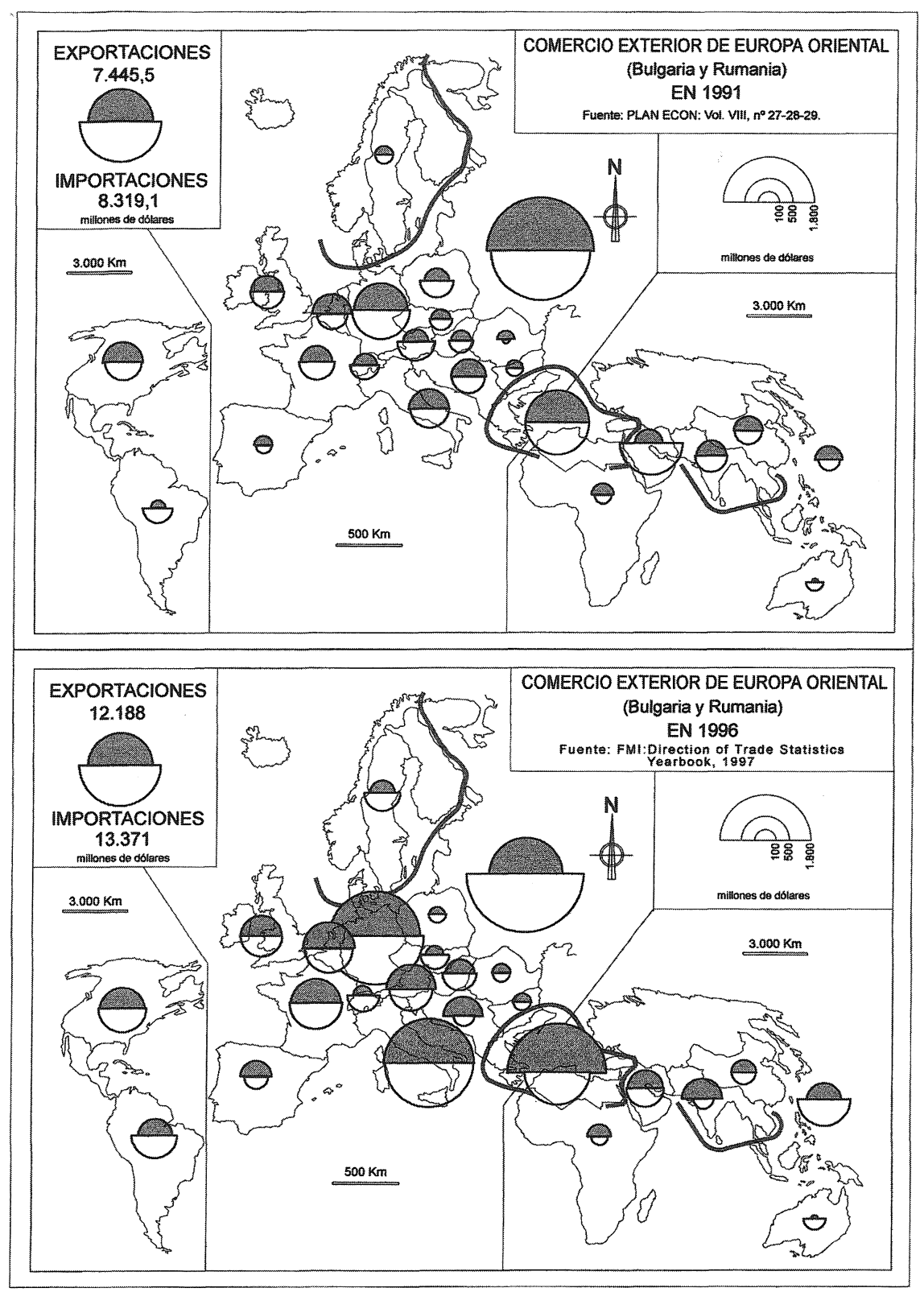

Fig. 5.-Geografía del comercio exterior de Europa oriental, en 1991 y 1996. 

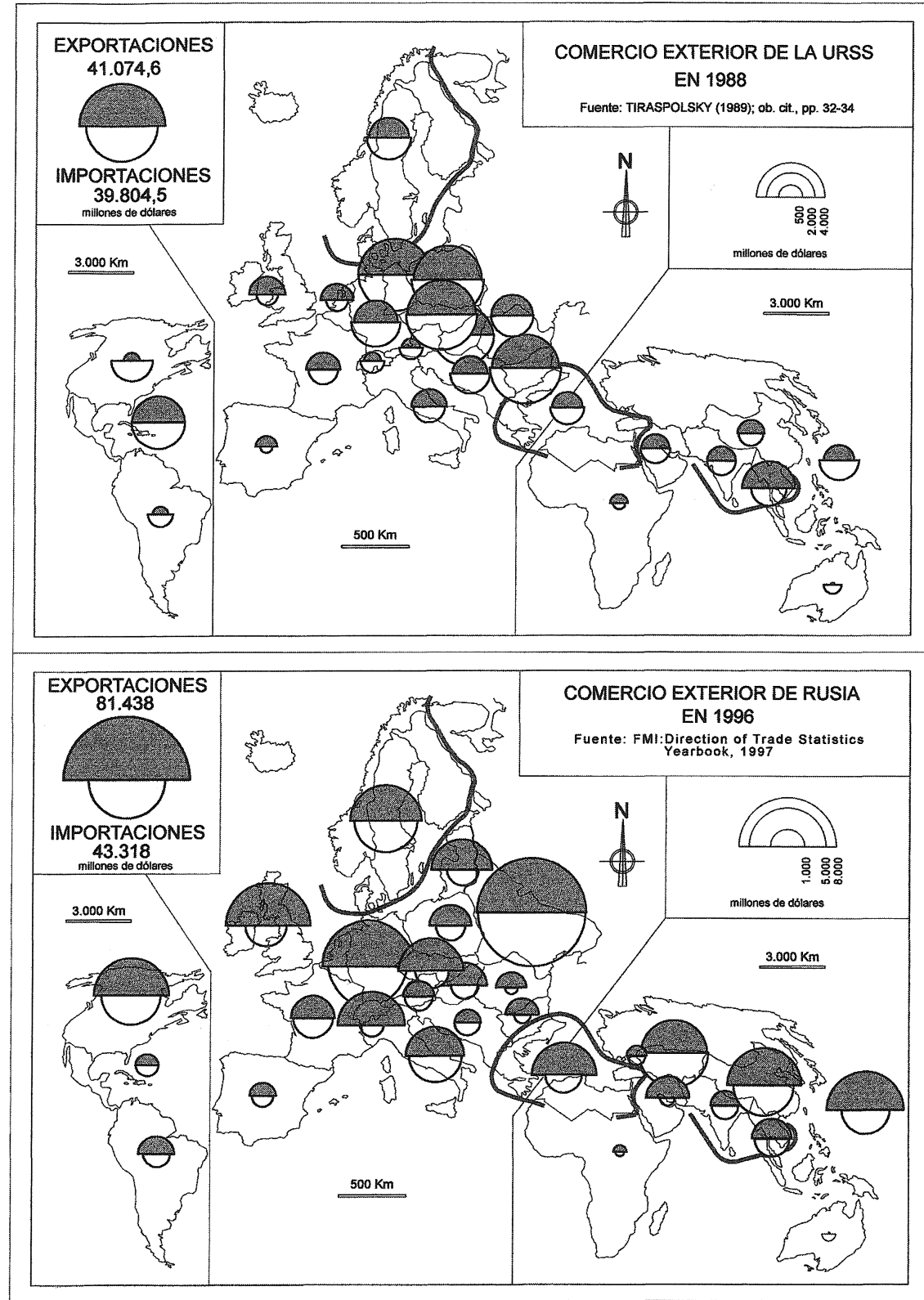

FIG. 6.-Geografía del comercio exterior de la URSS/Rusia, en 1988 y 1996. 
El mercado alemán tiene más importancia para Europa central (figura 4) ya que hacia él dirige un tercio de sus exportaciones (porcentaje superior al que representaba la URSS en 1989) y de allí procede la cuarta parte de las importaciones. Polonia, Chequia y Hungría se benefician de la proximidad geográfica al polo alemán y de una situación económica inicial más favorable. La presencia de Alemania es menor en el comercio de los países balcánicos (figura 5) que mantienen relaciones más estrechas con el área mediterránea, debido a la proximidad geográfica y económica (Labaronne, 1996 a).

$\mathrm{Al}$ igual que sus ex socios, Rusia (figura 6) está más vinculada a Europa occidental, que absorbe el $38,4 \%$ de las exportaciones rusas (cerca de la mitad si no se incluyen las ventas a los países de la Comunidad de Estados Independientes). Desde los años 1989-91 de la perestroika se han intensificado las relaciones con otras áreas industrializadas (Estados Unidos-Canada, Japón-NPI). El comercio con el continente asiático, históricamente conflictivo, muestra un gran dinamismo desde principios de los años 1980 (Tiraspolsky, 1989), sobre todo con la República Popular China, tercer socio comercial de Rusia, por detrás de Ucrania y Alemania. Las relaciones comerciales con los países en vías de desarrollo fueron más fluidas con los Estados vinculados a la estrategia internacional de la URSS (Afganistán, la India, el mundo árabe o Cuba). Las relaciones con Cuba, que durante tres décadas fue uno de los principales socios, conocen desde 1990 una fuerte contracción. La desintegración de la URSS redujo el comercio entre las repúblicas que la habían integrado (NU, 1996; Lavigne, 1997). Sin embargo, las relaciones se han incrementado notablemente en los últimos años (Sánchez, 1995). La cuarta parte del comercio ruso se dirige a los otros países de la CEI, a lo que contribuye la interdependencia económica heredada de los tiempos de la URSS.

Causas y consecuencias de la reorientación del comercio exterior

El hundimiento del comercio intrarregional y la reorientación de los flujos hacia el área de la OCDE han merecido la atención de numerosos estudiosos y analistas, que destacan como causas más importantes las siguientes: 
a) La disolución del CAEM en junio de 1991 (Budapest) significó la ruptura de vínculos anteriores. Desde entonces cada uno de los socios toma sus propias decisiones. Pero, en modo alguno, puede explicarse la readaptación geográfica de los flujos exclusivamente por la desaparición de aquella organización. En realidad el comercio intrarregional venía deteriorándose desde unos años antes.

b) El colapso de la economía soviética (Chavigny, 1996) y la descomposición territorial de la URSS que, hasta hace poco, ha sido el primer interlocutor de los PECO (Luengo, 1992; Szamuely, 1993).

c) El deseo de los países del Este de una mayor aproximación a la Unión Europea, de reincorporase a una zona que histórica y geográficamente consideran suya (Bayou, 1995 a). Los nuevos dirigentes eran reacios a intensificar relaciones con Rusia ya que no querían identificarse con el antiguo orden. En 1990 el presidente checo Havel denunciaba «la colonización soviética de los países europeos» (Bayou, 1995 b).

d) El atraso tecnológico, incompatible con los objetivos de forma económica, exigía intensificar relaciones con los países más desarrollados que es donde se encuentran los principales centros de innovación (Luengo, 1991). La autarquía de cuatro décadas se logró a un coste muy alto: obsolescencia del aparato productivo y escasa calidad de los artículos producidos.

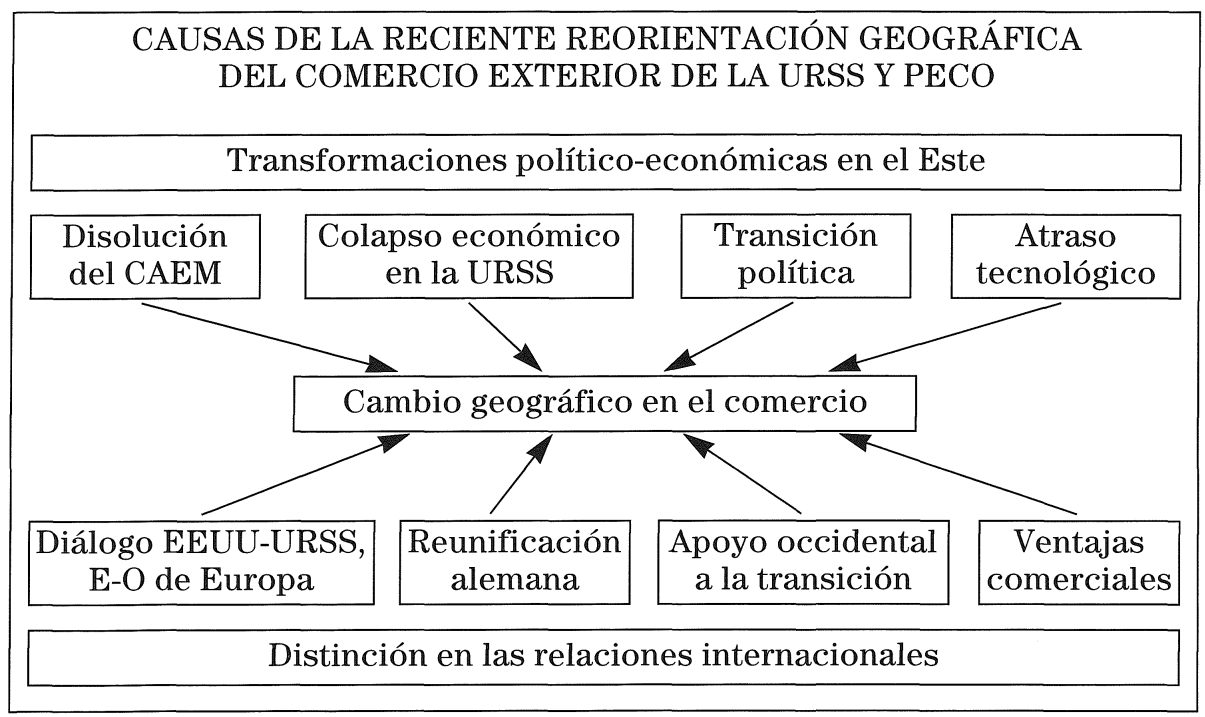


e) El clima de distensión política entre el Este y el Oeste, en las relaciones EEUU-URSS y en las relaciones intraeuropeas (Lavigne, 1989). A medida que los países del Pacto de Varsovia dejaban de ser una amenaza, las restricciones al comercio se fueron aligerando.

f) Las necesidades de la nueva Alemania brindan posibilidades a las exportaciones de Europa oriental. En este sentido, hay que recordar que la antigua RDA era, después de la URSS, el principal socio de los PECO.

g) Occidente observa, participa e incluso guía la transición en nombre de su propia seguridad económica y política, para evitar que la transición se torne incontrolable.

h) Los acuerdos de cooperación económica y comercial que se han firmado en fechas muy recientes y que hubieran sido inimaginables hace tan sólo una década. La mayor parte de los países de la OCDE han concedido a PECO el estatuto de nación más favorecida, son muchos los que tienen un acceso preferencial al mercado en virtud del Sistema de Preferencias Generalizadas (Lobejón, 1993; Chavigny, 1996). En el siguiente esquema se indican los acuerdos comerciales y de asociación firmados con Occidente, que hemos relacionado con los principales acontecimientos geoestratégicos (columna de la izquierda). En 1998, a resultas de las reformas emprendidas por Gorbachov, tuvo lugar el reconocimiento mutuo entre la CEE y el CAEM, dos organizaciones que hasta ese momento se habían dado la espalda. En los años siguientes se firmaron acuerdos comerciales con la Comunidad Europea. Pero es a partir de 1991 (disolución del CAEM, descomposición de la URSS) cuando se multiplican los acuerdos comerciales (ahora de la CEE con las repúblicas ex soviéticas y de la EFTA con PECO) y los acuerdos de asociación con la Comunidad, en los que se contempla el desarme arancelario con el fin de crear una zona de libre comercio en el plazo de diez años. Además los países del Este participan en las instituciones y organismos internacionales. Todos, excepto las nuevas repúblicas nacidas de la descomposición de la URSS, son miembros de la OMC.

En el capítulo de consecuencias hemos de destacar:

a) La drástica reducción de las importaciones y exportaciones. La ruptura de los vínculos entre los antiguos socios CAEM no fue compensada con el aumento de los flujos con el Oeste, al menos en los primeros momentos de la transición. La entrada en vigor de los acuerdos 
CAMBIOS EN EL COMERCIO EXTERIOR DE LOS PAÍSES DEL ESTE...

EVOLUCIÓN INSTITUCIONAL DE LAS RELACIONES COMERCIALES DE EUROPA DEL ESTE

\begin{tabular}{|c|c|c|c|c|c|}
\hline & & \multicolumn{3}{|c|}{ Acuerdos comerciales } & \multirow{2}{*}{\begin{tabular}{|c|}
$\begin{array}{c}\text { Acuerdos } \\
\text { de asociación }\end{array}$ \\
$\begin{array}{c}\text { De la CEE/UE } \\
\text { con }\end{array}$
\end{tabular}} \\
\hline Año & $\begin{array}{c}\text { Principales } \\
\text { acontecimientos }\end{array}$ & $\begin{array}{c}\text { De la } \mathrm{CEE} / \mathrm{UE} \\
\text { con }\end{array}$ & $\begin{array}{l}\text { De la EFTA } \\
\text { con }\end{array}$ & $\begin{array}{l}\text { De Norue- } \\
\text { ga, Finlan- } \\
\text { dia y Suiza } \\
\text { con }\end{array}$ & \\
\hline 1988 & $\begin{array}{l}\text { Reconocimiento } \\
\text { mutuo de la CEE } \\
\text { y el CAEM }\end{array}$ & $\begin{array}{l}\text { Hungría } \\
\text { Checoslovaquia }\end{array}$ & & & \\
\hline 1989 & $\begin{array}{l}\text { Cae el muro de } \\
\text { Berlín }\end{array}$ & $\begin{array}{l}\text { Polonia } \\
\text { URSS }\end{array}$ & & & \\
\hline 1990 & $\begin{array}{l}\text { Reunificación } \\
\text { alemana }\end{array}$ & $\begin{array}{l}\text { Bulgaria } \\
\text { Rumania }\end{array}$ & & & \\
\hline 1991 & $\begin{array}{l}\text { Desaparece el } \\
\text { CAEM } \\
\text { Independencia } \\
\text { de Estonia, } \\
\text { Letonia y Lituania } \\
\text { Desaparece la } \\
\text { URSS y nace la } \\
\text { CEI }\end{array}$ & & Checoslovaquia & & $\begin{array}{l}\text { Polonia } \\
\text { Hungría } \\
\text { Checoslovaquia }\end{array}$ \\
\hline 1992 & & Estonia & $\begin{array}{l}\text { Polonia } \\
\text { Rumania }\end{array}$ & $\begin{array}{l}\text { Estonia } \\
\text { Letonia } \\
\text { Lituania }\end{array}$ & \\
\hline 1993 & $\begin{array}{l}\text { Separación de las } \\
\text { repúblicas Checa } \\
\text { y Eslovaca }\end{array}$ & Letonia & $\begin{array}{l}\text { Chequia } \\
\text { Eslovaquia } \\
\text { Bulgaria } \\
\text { Hungría }\end{array}$ & & $\begin{array}{l}\text { Chequia } \\
\text { Eslovaquia } \\
\text { Rumania } \\
\text { Bulgaria }\end{array}$ \\
\hline 1994 & & $\begin{array}{l}\text { Lituania } \\
\text { Rusia } \\
\text { Ucrania } \\
\text { Moldavia }\end{array}$ & & & \\
\hline 1995 & & $\begin{array}{l}\text { Eslovenia } \\
\text { Bielorrusia }\end{array}$ & & & $\begin{array}{l}\text { Estonia } \\
\text { Letonia } \\
\text { Lituania } \\
\end{array}$ \\
\hline
\end{tabular}

FuEnTE: Chavigny, R. (1966): Spécialisation interationale et transition en Europe Centrale et Orientale, L'Harmattan, París; Eurostat-Statistiches Bundesamt. Monographie par pays: Estonie (1993); Lettonie (1993); Lituanie (1993); Etats de la CEI (1994); Europe Centrale et Orientale (1994); OCDE (1994): Obstacles aux échanges avec les économies en transition, OCDE,París; OCDE (1994): Intégrer les économies de marché naissantes dans le système commercial internacional, OCDE, París. 
comerciales explica el reciente ascenso de las importaciones y exportaciones (figura 2). La inversión extranjera también ha contribuido al éxito de las exportaciones (FMI, 1997).

b) El saldo negativo en la balanza comercial de PECO (figura 7), que ahora han de adquirir los productos energéticos a precios más elevados que en el periodo CAEM, mientras que las exportaciones no avanzan al mismo ritmo por la falta de competitividad. En Rusia el resultado positivo a favor de las exportaciones se debe a las ventas de combustibles.

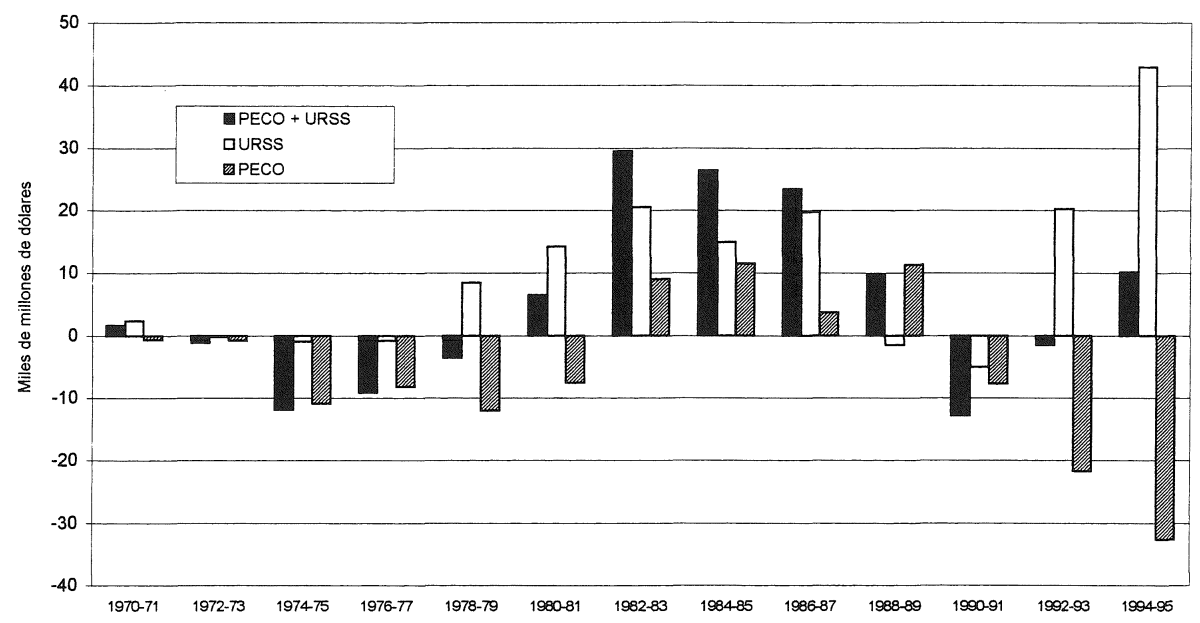

FIG. 7.-Balanza comercial (1970-95).

Composición de los intercambios

La estructura de las exportaciones e importaciones es diferente según los países con los que se mantienen relaciones comerciales.

La especialización en los intercambios intraCAEM.-El comercio intraCAEM, según los principios de la división internacional socialista del trabajo, se basaba en relaciones de complementariedad y acuerdos de especialización de la producción. Como ha destacado Violette Rey (1996), se impuso una asimetría de los intercambios inversa a la de la economía capitalista, ya que la Unión Soviética suministraba combustibles (petróleo, gas natural, carbón, electricidad) y minerales, a cambio de maquinaria, bienes de equipo y productos agropecuarios. 


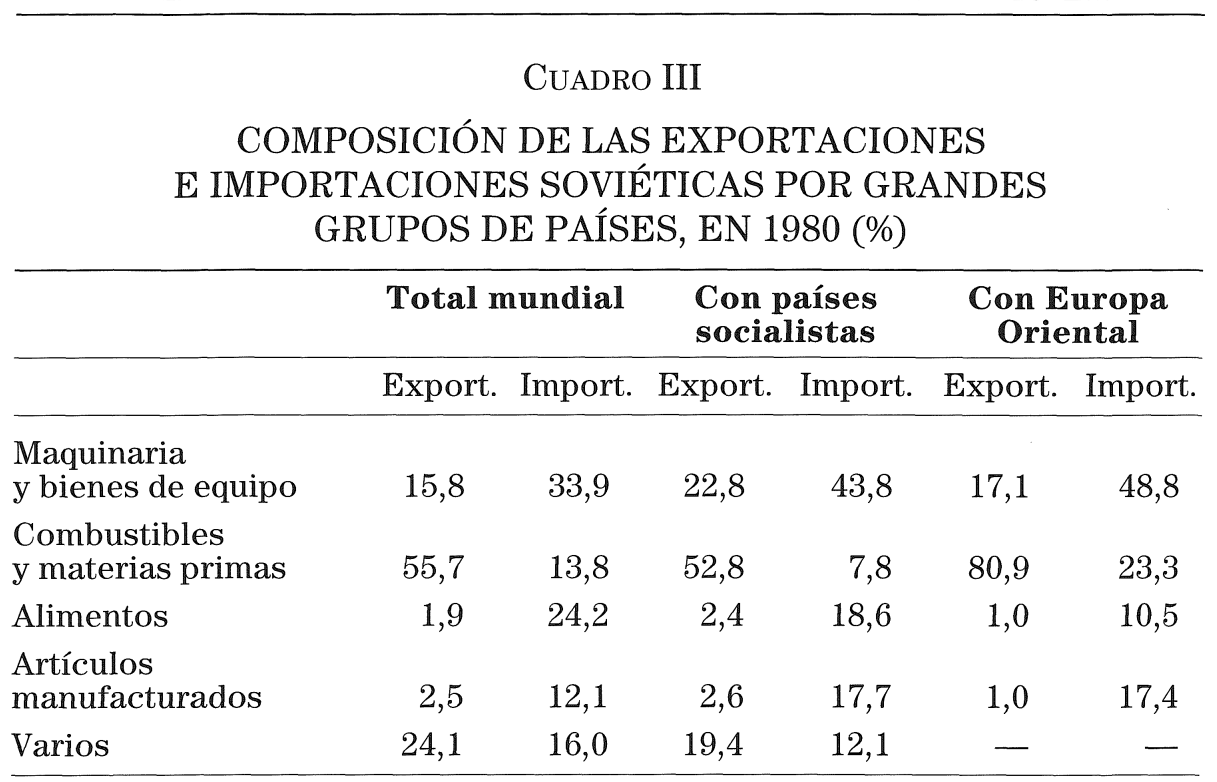

Fuente: Graziani, G. (1982): Comecom, domination et dépendances, F. Maspero, París, p. 52.

En el esquema de la página siguiente, elaborado a partir de las obras de Graziani (1982) y Bogomolov (1989), se recoge la especialización productiva de los diferentes países a principios de los años $1980^{6}$. Los valores indican el coeficiente de exportación como porcentaje de la producción nacional. A mayor valor, mayor grado de especialización productiva orientada a la exportación. No deben sorprender las cifras relativamente bajas de la URSS, cuya economía era la más diversificada de la región y que contaba con un mercado interior de grandes dimensiones. Allí un 10\% indica una gran especialización. La Unión Soviética exportaba buena parte del petróleo y de la producción de automóviles, armas y equipos para centrales nucleares.

Los PECO, a excepción de Hungría y Rumanía, concentraban la mitad de la capacidad exportadora en el epígrafe de maquinaria y material de transporte. Destacaba, por ejemplo, la construcción de barcos en Alemania y Polonia, automóviles y autocares en Hungría y Checoslova-

${ }^{6}$ La forma que hemos dado al esquema no muestra la dirección de los flujos, ya que cada país exportaba a todos los socios del CAEM. Sin embargo, el comercio intrarregional tenía un marcado carácter radial en la medida en que el mercado soviético era el más importante para todos y cada uno de los países del Este. 
quia. Este último era el único país del CAEM especializado en la producción de tranvías. Además de fabricar autocares, Hungría se especializó en industria farmacéutica. Los carromatos eléctricos eran fabricados en Bulgaria. En las exportaciones de Rumanía sobresalían los sectores relacionados con el petróleo. En los dos países balcánicos destacaban las ventas de productos agroalimentarios. La especialización se mantuvo pese a la resistencia de varios países. Los dirigentes búlgaros no se sentían complacidos con el papel secundario que se atribuía a su economía especializada en bienes agropecuarios (Chavigny, 1996). Por su parte, los líderes de la República Democrática Alemana y Checoslovaquia creían que el CAEM frenaba su propósito de especializarse en bienes de equipo con mayor contenido tecnológico (Palazuelos, 1996).

Sobre las relaciones entre la URSS y los PECO ha prevalecido la tesis de saqueo, expolio, rapiña de las economías subordinadas a una gran potencia (la URSS es un país veinte veces mayor que el resto del área, su población triplica a la del conjunto de sus socios y posee enormes riquezas energéticas y minerales en el subsuelo). Sin embargo, no faltan las opiniones de signo contrario. Esto es, que la URSS fue explotada por los países del CAEM sobre todo cuando, en plena crisis mundial de los años 1970, les vendía petróleo a precios inferiores a los del mercado mundial. En 1979, según la revista Financial Times (Lavigne, 1980), el precio de venta del petróleo ruso era un $40 \%$ inferior al de la OPEP. Por otra parte, el precio de los bienes de equipo que la Unión Soviética compraba a sus socios eran de menor calidad y a precios más altos de los que podía obtener en Occidente (Rocher, 1996).

En realidad, la URSS subvencionaba indirectamente a sus socios, ya que hubiese podido vender el petróleo a Occidente a un precio más elevado. Economistas americanos han estimado que estas subvenciones se elevaban en 1981 a 100 mil millones de dólares (Seurot, 1989). En contrapartida, la Unión Soviétoca obtenía beneficios no convencionales (Graziani, 1982; Lavigne, 1990), ya que de esta forma «compraba», por así decirlo, la cohesión política del sistema socialista, garantizaba su estabilidad. Además aseguraba el aprovisionamiento de productos estratégicos (equipamientos de la RDA y Checoslovaquia) y las ventas soviéticas.

La orientación forzada de los intercambios durante el periodo CAEM consolidó una fuerte dependencia de los países del Este respecto a la 


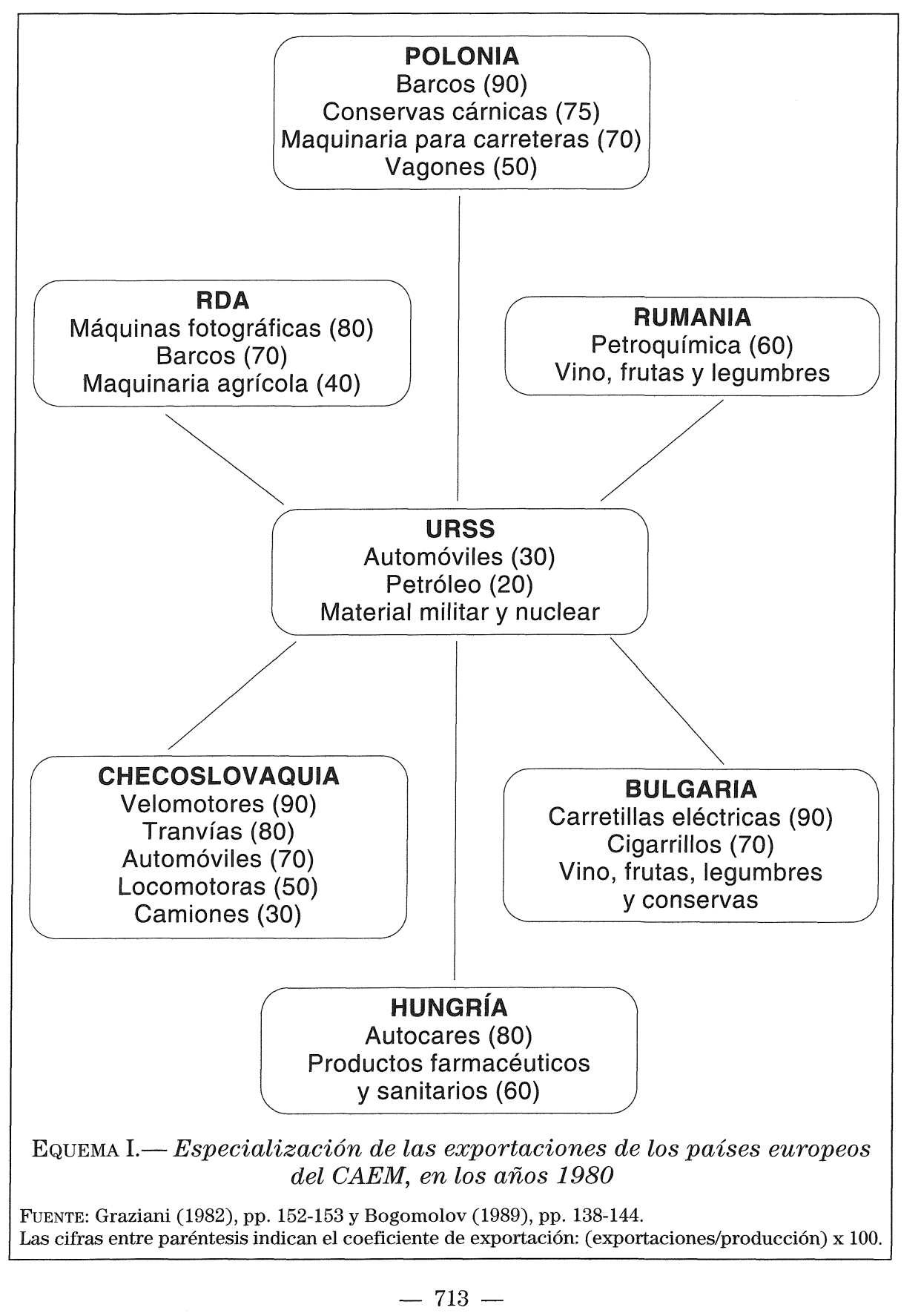


URSS, que a mediados de los años 1970 cubría el 75\% de las necesidades de petróleo, el 100\% del gas y el 60\% del carbón (Lavigne, 1980). La oferta ilimitada de la URSS, los precios artificialmente bajos, el consumo excesivo del sector industrial - tres veces superior al de Occidente, para una producción similar (Rey, 1996) —, han tenido un efecto negativo sobre la calidad y el nivel tecnológico de la producción. A largo plazo el sistema ha resultado perjudicial para todos los socios.
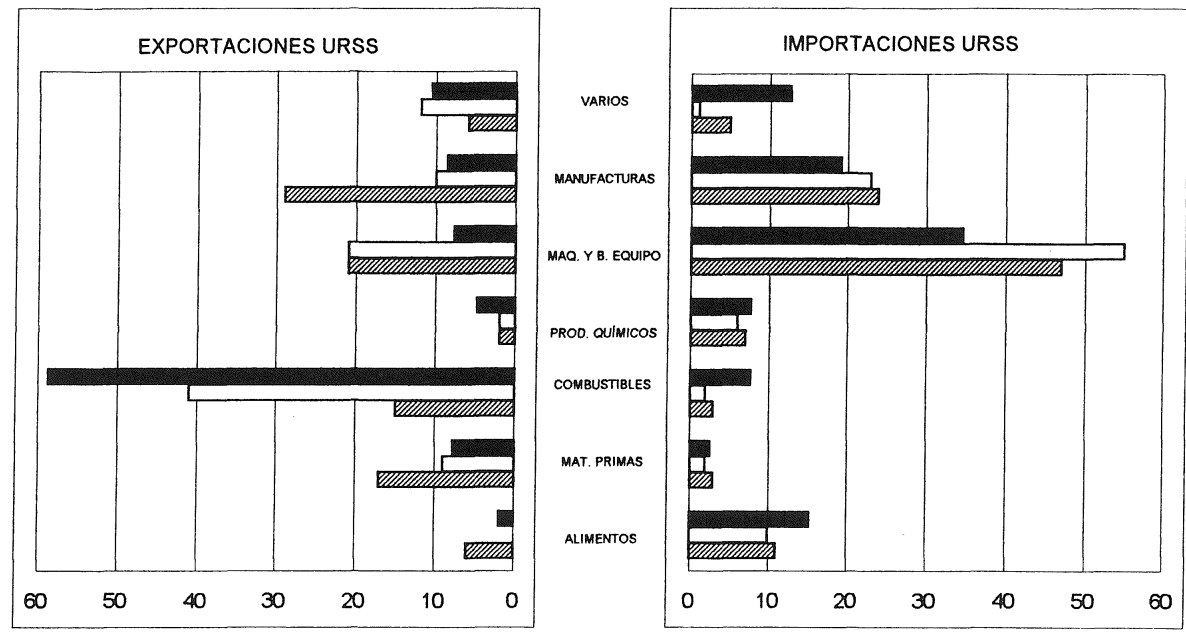

\begin{tabular}{|lll|}
\hline एवि & $\square$ & \\
1970 & 1980 & 1993 \\
\hline
\end{tabular}

FIG. 8.-Estructura del comercio URSS-PECO (\%).

Los países del Este siguen dependiendo de las exportaciones rusas de hidrocarburos (figura 8), pese a que las cifras han disminuido de forma ostensible. Si en 1989 les proporcionaba 56,4 millones de toneladas de crudo, en 1992 la cantidad era de unos 20 millones (Bayou, 1995 b). La venta de maquinaria y manufacturas rusas también se ha reducido ya que los consumidores de los PECO prefieren los bienes occidentales (Bayou, 1995 a; Rocher, 1996). Como en años anteriores, Rusia adquiere en la región bienes de equipo. En conjunto, la composición del comercio RusiaPECO sigue siendo la misma después de la desaparición del CAEM. 
Estructura del comercio Este-Oeste.-Conviene recordar que en el momento actual Occidente es el principal interlocutor de Europa Central y Oriental (figura 9). El comercio Este-Oeste se caracteriza por la asimetría de los intercambios y se encuadra en la modalidad de relaciones Norte-Sur. El Este exporta recursos energéticos, materias primas (Rusia) y manufacturas que incorporan escaso valor añadido: textil, vestido, calzado, cuero... (los PECO), cuya demanda mundial progresa muy lentamente o incluso se reduce. Producciones que se enfrentan a la competencia de los NPI y la producción occidental y que por ello son objeto de medidas proteccionistas.

El acceso a los mercados occidentales previsto en los acuerdos comerciales y de asociación no ha sido tan generoso como se esperaba. El proteccionismo no ha desaparecido en la práctica. Se siguen manteniendo muchas limitaciones (Landau, 1992; Graziani, 1995; FMI, 1997; Lavigne, 1997), restricciones sanitarias, medidas antidumping, contingentes para determinados productos: agrícolas, textiles, aluminio, acero..., ya que los países del Este pueden representar una evidente competencia. Por ejemplo, se imponen cuotas al acero checo cuando este acero apenas cubre el $1 \%$ del mercado comunitario. En cambio, Bruselas proponía a los paises bálticos que aumentasen sus exportaciones de plátanos y piñas (Attali, 1994), limitando las ventas de artículos agrarios que producen en abundancia. Con estas medidas, los países industrializados castigan las exportaciones de los países del Este en unos momentos difíciles de la transición hacia la economía de mercado. La caída del muro de Berlín debe ir acompañada de la desaparición de los obstáculos que dificultan la plena inserción de los PECO en la economía mundial. Como dice el profesor Vidal Villa (1990), hace falta una perestroika en Occidente.

Las exportaciones de maquinaria han tenido muy poca importancia. En el momento actual apenas representan el 20\% de todas las ventas a Occidente. Esto es así por el atraso tecnológico, consecuencia del modelo de organización económica imperante durante más de cuarenta años. La división internacional socialista del trabajo aisló a estos países de los flujos internacionales, condición indispensable para la modernización. Como ya se ha indicado, tal organización se mantuvo a un coste muy alto: aparato productivo obsoleto y deterioro de la calidad de los productos. El colapso de la economía soviética y la descomposición de la URSS representó un duro golpe para las industrias orientadas hacia aquel mercado. La reorientación geográfica de los intercambios ha puesto de 
manifiesto la escasa competitividad en estas exportaciones cuando tratan de dirigirse hacia mercados que son mucho más exigentes.

Europa Oriental acude a los mercados occidentales para adquirir alimentos y bienes de equipo. Estos últimos representan en la actuali-
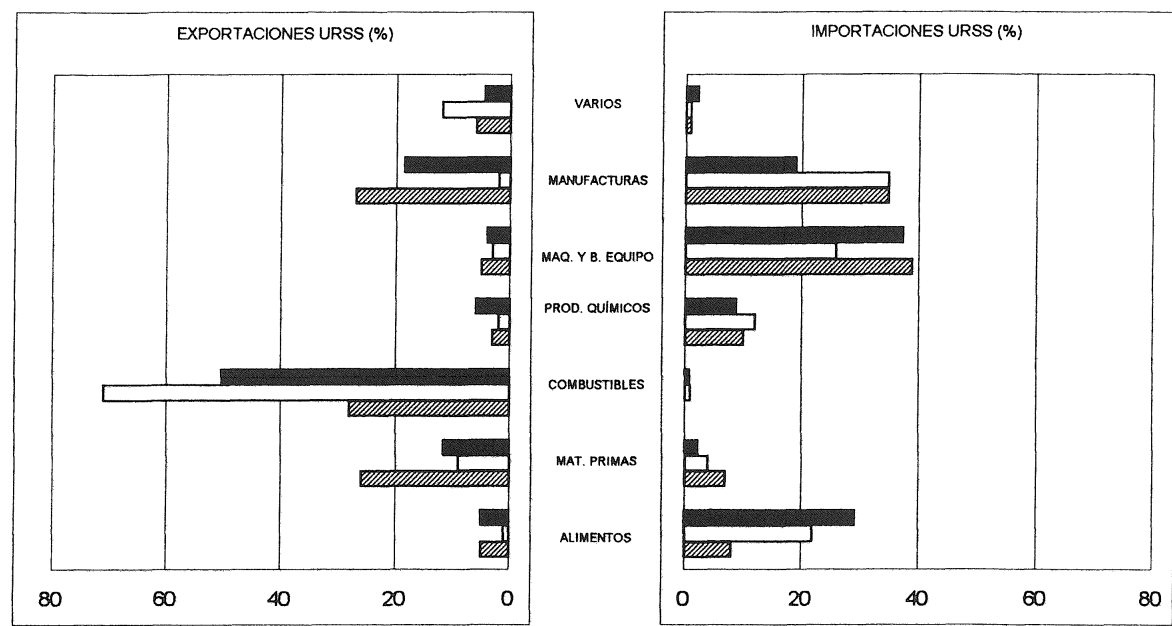

\begin{tabular}{|lcc|}
\hline 1970 & $\square$ & 1993 \\
\hline
\end{tabular}
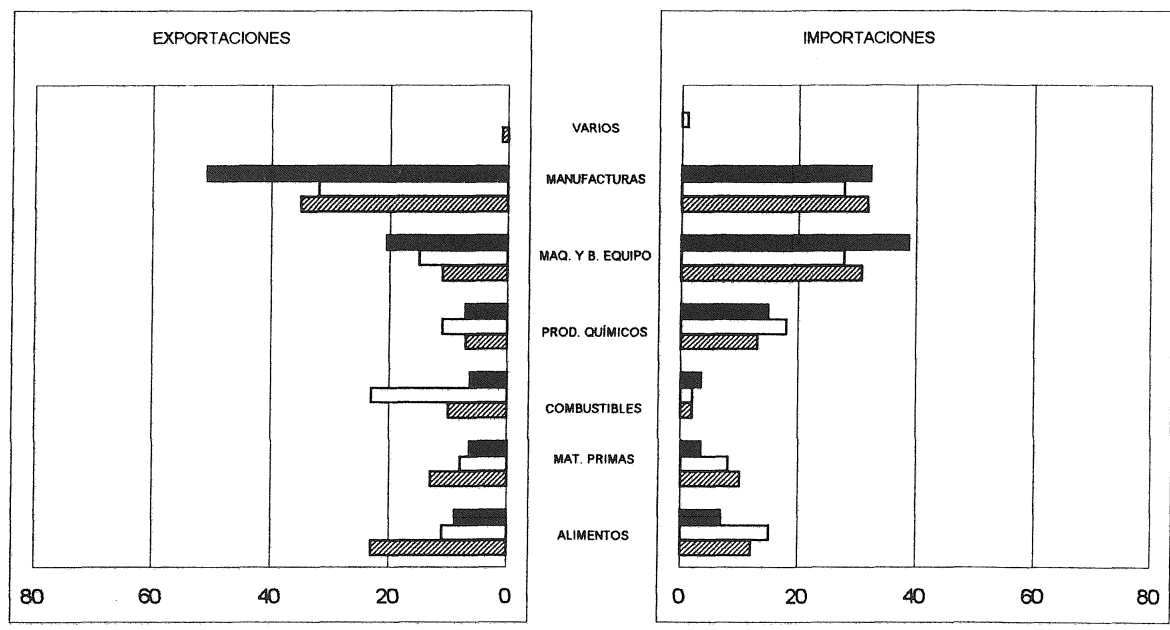

FIG. 9.-Estructura del comercio exterior con Occidente (\%). 
dad el $40 \%$ de las importaciones. La compra de cereales, carne, productos lácteos, etc., constituye un componente fundamental de la política comercial rusa (el 30\% de todas las importaciones en 1994). Blotnicki (1990) atribuía estas importaciones a la baja productividad del sector agrario, la pobre dotación en infraestructuras, los problemas de almacenamiento y la obsolescencia de la maquinaria. Factores a los que se añaden, en fecha reciente, las dificultades del sector a raíz de la privatización de la producción, el encarecimiento de los productos fitosanitarios, la caída de la inversión y las ayudas (subvenciones) a la producción en la UE, que favorecen las exportaciones comunitarias (Labaronne, 1996 b). Precisamente, el aspecto más novedoso de estas importaciones es que buena parte proceden de la Comunidad Europea (Wild, 1995). Antes del embargo de 1980, EEUU era con diferencia el primer proveedor.

El comercio con el Sur.-Las relaciones con los países del Tercer Mundo se basaban en principio de la solidaridad política con países que estaban siguiendo el «camino socialista hacia el desarrollo» (Lavigne, 1997). Siempre fue marginal (cuadro II) y cada vez más subordinado a los intereses económicos del Este. Los productos primarios han dominado de forma aplastante en las importaciones de los países socialistas (figura 10). El primer puesto ha correspondido a los alimentos, seguidos de las materias primas. En los últimos años aumenta la importancia relativa de la maquinaria y las manufacturas intensivas en mano de obra. Hay que destacar asimismo la importancia relativa de los combustibles en las compras de PECO. Sin duda estas importaciones se mantendrán o incluso aumentarán en el futuro ya que, como se ha explicado, los suministros soviéticos han menguado.

A cambio de materias primas, productos agrarios y recursos energéticos, Europa del Este y la URSS suministraban manufacturas y bienes de equipo, sobre todo artículos que no podían venderse en Occidente y que, con frecuencia, no se adaptaban a las necesidades del Sur. La pérdida de importancia relativa de los equipos se relaciona con la reciente industrialización de algunos países en vías de desarrollo (Graziani, 1990). Llama la atención la importancia que llegaron a alcanzar las exportaciones de armas y equipos militares soviéticos (incluidos en «varios»). En los años 1970 representaban cerca del 50\% de todas las ventas a los PVD, con Oriente Medio como mercado principal.

$$
-717-
$$



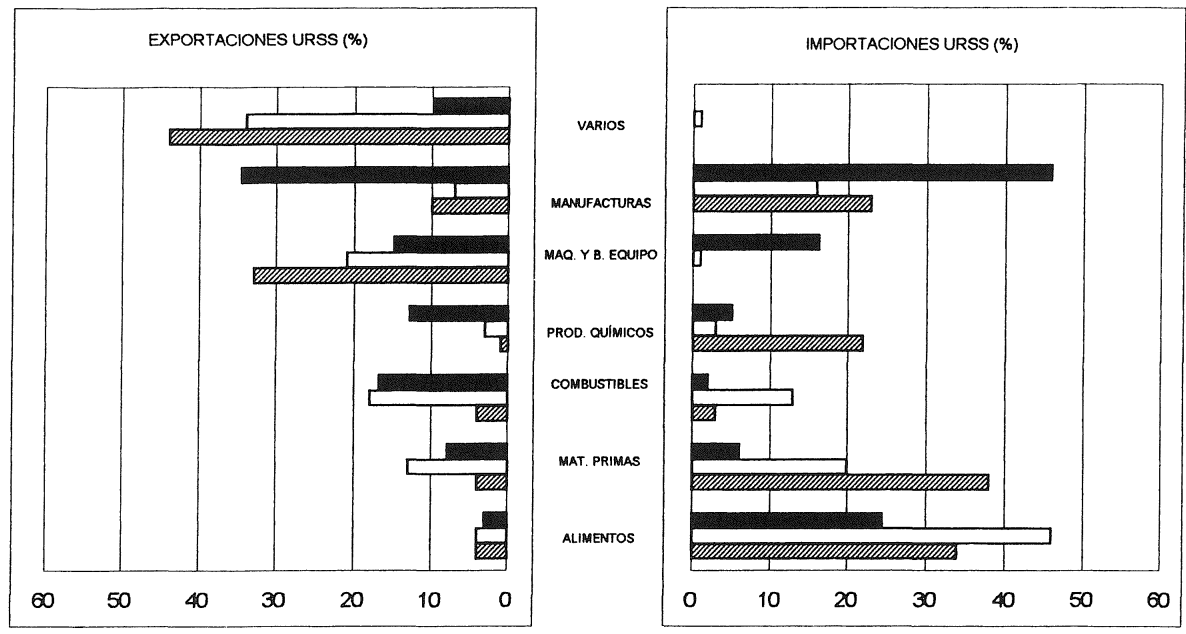

\begin{tabular}{|lll|}
\hline mans & $\square$ & \\
1970 & 1980 & 1993 \\
\hline
\end{tabular}
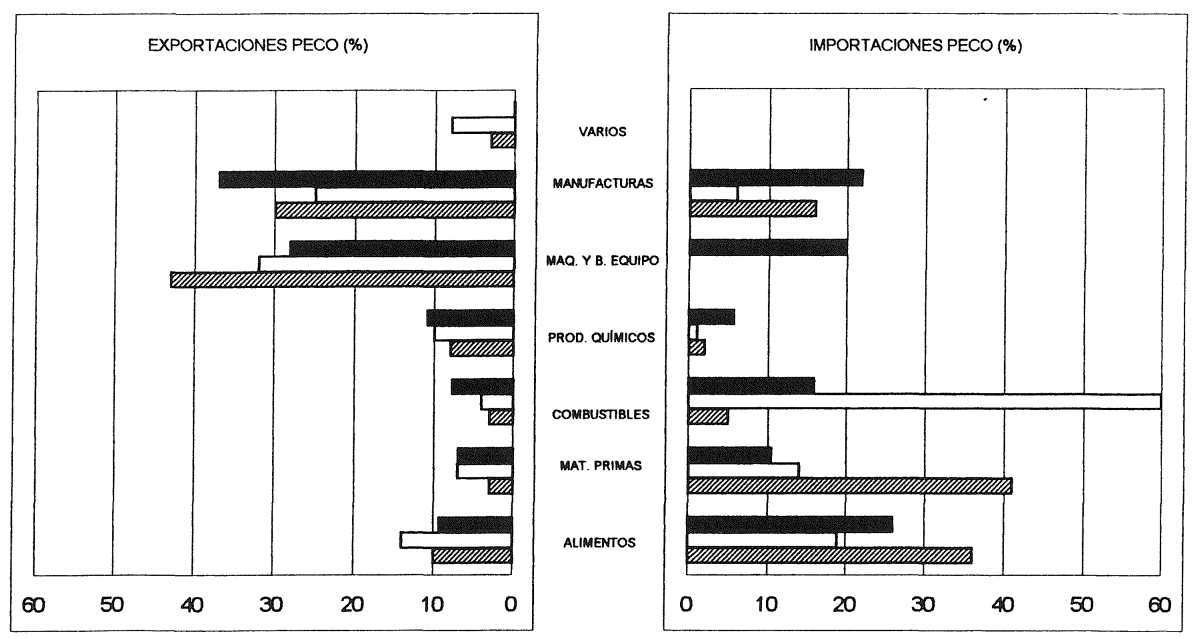

Fig. 10.-Estructura del comercio con países en desarrollo (\%). 
Balance y perspectivas de las relaciones comerciales de Europa del Este

Durante cuarenta años, una parte de Europa permaneció relativamente aislada del resto del mundo. El modelo de desarrollo adaptado relegó de las prioridades el comercio con otras regiones, considerándose como un instrumento que permitía cubrir las insuficiencias de la producción interna. Como han destacado varios autores (Cole, 1969; Carrière, 1977; Brand, 1982; Seurot, 1987; Lobejón, 1995), la planificación centralizada manifestaba una fuerte aversión por el comercio internacional. Los planificadores se mostraban desconfiados frente al comercio exterior, entre otras razones, porque la planificación es mucho más fácil en un espacio económico cerrado que en otro con comercio exterior activo. Esta concepción se modificó ligeramente en los años 1960 coincidiendo con el inicio de la apertura exterior. Fue entonces cuando los países del Este comenzaron a considerar el comercio como factor de crecimiento. Las exportaciones seguían teniendo como objetivo principal la obtención de divisas necesarias para cubrir las importaciones, pero constituían además un estímulo para el desarrollo de sectores capaces de arrastrar al resto de la economía.

Desde hace poco las cosas han cambiado y Europa central y oriental busca su plena inserción exterior, que no está exenta de dificultades. Entre los rasgos más característicos de los últimos años hemos de destacar los siguientes:

a) El cambio espectacular en la distribución geográfica. Los países del CAEM, en particular la URSS, que habían sido el origen y el destino fundamental de los intercambios, han cedido su protagonismo a los países capitalistas desarrollados.

b) Hoy la Unión Europea es con diferencia el primer socio comercial de la Europa del Este. Sin duda, la reciente ampliación a dos países nórdicos (Suecia y Finlandia) y uno alpino (Austria), con quienes PECO han mantenido tradicionalmente relaciones privilegiadas, constribuirá a estrechar y consolidar sus vínculos.

c) Las relaciones comerciales entre los países del Este y la Unión Europea son más importantes para los primeros, dado el considerable peso del comercio intracomunitario. En 1995, según la Organización Mundial del Comercio, la Unión Europea absorbió la mitad de las ex-

$$
-719-
$$


portaciones del Este, mientras que la Comunidad dirigió hacia el Este el $4,4 \%$ de sus exportaciones (el 12\% de las extracomunitarias). Europa oriental actúa como periferia de la Unión Europea y es obvio que en caso de perturbación los más afectados serán los países del Este.

e) La sustitución de la URSS por Occidente ha modificado la estructura de los intercambios. Antes predominaban las exportaciones de maquinaria, ahora las exportaciones se orientan a productos con escaso valor añadido y recursos energéticos (en el caso de Rusia). Los bienes de equipo, los productos tecnológicamente avanzados y manufacturas diversas representan el grueso de las importaciones, que compiten sin dificultad con la producción autóctona, contribuyendo a la caída de la producción y el aumento del desempleo (Lobejón, 1995). Con todo, la adquisición de maquinaria y equipo constituye un buen presagio para el crecimiento futuro de estos países.

f) La balanza comercial es deficitaria debido precisamente a la diferente estructura de las exportaciones e importaciones. El positivo saldo comercial de Rusia se debe a las masivas exportaciones de combustibles y al hecho de que las importaciones son muy limitadas. Las fluctuaciones de los precios de los productos energéticos pueden afectar gravemente a la economía rusa.

g) Los países occidentales, después de haber facilitado el acceso a sus mercados de los productos del Este, han adoptado una actitud más proteccionista al sentirse potencialmente desestabilizados por la importación de ciertos productos. Estas medidas dificultan la plena inserción de las economías postcomunistas al mercado mundial.

Ante estos problemas, los países del Este deberían revitalizar el comercio intrarregional. Sería natural dada la complementariedad de sus economías. La cooperación con los PECo es básica para Rusia ya que son el puente hacia Europa occidental. En aquellos países los productos rusos son más fácilmente comercializables. Por su parte, Rusia constituye el mercado lógico para las exportaciones agropecuarias e industriales de PECO. El comercio mutuo es necesario para que sigan funcionando las infraestructuras y los equipamientos. El buen funcionamiento de ciertos equipos depende del suministro de piezas de recambio compatibles, producidas por uno u otro de los ex socios CAEM. Por ejemplo, en 1990 circulaban por la URSS 100.000 autocares Ikarus húngaros (Chavigny, 1996). Ciertos bienes intermedios tecnológicamente an- 
ticuados no se fabrican en el Oeste y, en consecuencia, no pueden ser importados más que de otros países del Este.

Con el fin de mantener cierto nivel de intercambio, los antiguos miembros del CAEM han firmado acuerdos y alianzas económicas, entre los que destacan: el Acuerdo Centroeuropeo de Libre Comercio (ACELC), más conocido como grupo de Visegrado y que engloba a Polonia, Hungría, las repúblicas Checa y Eslovaca y Eslovenia; el Consejo Báltico, con Estonia, Letonia, Lituania, Rusia, Polonia, Países Escandinavos y Alemania; la Zona de Cooperación Económica del Mar Negro, que integra a Bulgaria y Rumanía, junto con Turquía, Grecia y las repúblicas occidentales de la CEI. Los intentos de crear una zona de libre comercio en la Comunidad de Estados Independientes aún no han prosperado. Estas y otras iniciativas permitían, como ya está ocurriendo (FMI, 1997), a la reactivación del comercio entre los países de la región. Otros objetivos de los acuerdos son: la cooperación en la construcción de infraestructuras y la protección del medio ambiente. En cualquier caso, manifiestan el deseo de romper con la centralización pasada (Bayou, 1995 b). Sin duda contribuirán a la estabilidad política de la región y a la reestructuración de las economías, factores fundamentales para que Europa del Este estreche relaciones con el resto del mundo.

\section{BIBLIOGRAFÍA}

AA VV (1984): Geografia României, Editura Academiei Republicii Socialiste Româria, Bucarest, vol. II (capítulo 8, pp. 449-460).

ANDREFF, W. (1989): «Las relaciones económicas entre la Comunidad Económica Europea y el Consejo de Ayuda Económica Mutua», Información Comercial Española, 674, pp. $37-52$.

- (1992): «La desintegración económica internacional de Europa del Este», Información Comercial Española, 708-709, pp. 119-150.

- (1993): La crise des économies socialistes: la rupture d'un système, Presses Universitaires de Grenoble, Grenoble (en especial el apartado $5 .^{\circ}$ del capítuló $6 .^{\circ}$ : «La désintegration internationale des économies socialistas»).

ARTEAga MARTín, F. (1989): «Las relaciones económicas Este-Oeste. Repercusiones sobre la estabilidad internacional», Información Comercial Española, 668, pp. 41-57.

ATLAS OXFORD (1963): The USSR and Eastern Europe, Oxford University Press, 134 p.

Attali, J. (1994): Europa(s), Seix Barral, Barcelona, 187 p.

BALtZinger, H. y PINEYe, D. (1994): «Les relations économiques de la Russie avec l'AsiePacifique», Les Courrier des Pays de l'Est, 392, pp. 49-59.

Banco Mundial (1996): Informe sobre el desarrollo mundial 1996. De la planificación centralizada a la economía de mercado, BM, Washington, DC, 275 p. 
BAREA, M. ${ }^{a}$ T. (1989): «Relaciones de los países europeos del CAEM con los países en desarrollo», Información Comercial Española, 674, pp. 61-68.

BAYOU, C. (1995 a): «La présence économique occidentale en Europe Centrale et Orientale: la place de la France», en Lhomel, E., coord.: Transitions économiques à l'Est (1989-1995), CEDUCEE, La Documentation Française, París, 219-248.

_ (1995 b): «Les relations économiques CEI-pays d'Europe centrale et orientale: les tâtonnements de l'apres CAEM», Le Courrier des Pays de l'Est, 397-398, pp. 172- I 84.

Benaroya, Fr.; Bourgoin, L. y SzynaL, J. (1996): «L'ouverture commerciale des pays d'Europe centrale et orientale: trajectoires, forces sous-jacentes et perspectives», Le Courrier des Pays de l'Est, 410, pp. 3-14.

BLOTNICKI, L. (1990): «Les échanges agro-alimentaires et agro-industriels de l'URSS, en Lavigne, M.: L'URSS en transition: un nouveau marché, Centre Français du Commerce Extérieur, París, pp. 143-161.

Bogomolov, O. (1989): Socialisme et compétitivité. Les pays de l'Est dans l'économie mondiale, Presses de la Fondation Nationale des Sciences Politiques. París, $247 \mathrm{p}$.

Brand, D. (1982): L'Union Soviétique, Sirey, París, 211 p.

CARRIÈre, P. (1977): L'économie de l'URSS, Masson, París, 250 p.

Chavigny, R. (1992): «La difficile réorientation des échanges des cinq pays d'Europe Centrale et Orientale», Le Courrier des Pays de l'Est, 373, pp. 3-13.

_ (1995): «Convertibilité et spécialisation internationale dans les économies est-européennes en transition», Revue d'Études Comparatives Est-Ouest, vol. 26, núm. 1, pp. $35-65$.

- (1996): Spécialisation internationale et transition en Europe Centrale et Orientale, L'Harmattan, París, 225 p.

Cole, J. (1969): L'URSS, Armand Colin, París, 237 p.

Crosnier, M. ${ }^{a}$ A. y Holcblat, N. (1991): «Tableau de bord économique 1991 des sept pays d'Europe Centrale et Orientale», Le Courrier des Pays de l'Est, 364, pp. 35-49.

CsABA, L. (1989): «Quo vadis COMECON?, le point de vue des petits pays de l'Europe de l'Est», Le Courrier des Pays de l'Est, 344, pp. 3-23

(1990): Eastern Europe in the world economy, Cambridge University Press, Cambridge, $403 \mathrm{p}$.

(1991): «Auge y caída del COMECON». Cuadernos del Este, 2, pp. 67-72.

DANGERFIELD, M. V. (1995): «The economic opering of Central and Eastern Europe: continuit and change in foreign economic relations, Revue d'Integration Européenne, 1, pp 5-42.

Diambou, J. (1980): «Faiblesses et qualites des relations Est-Sud», en Lavigne, M., coord.: Stratégies des pays socialistes dans l'échange international, Economica. París, pp. 119-1 32.

FMI (1997): Perspectivas de la economía mundial. Globalización, oportunidades y desafíos, Fondo Monetario Internacional, Washington, DC, $221 \mathrm{p}$.

GACS, J. y WiNCLKER, G., eds. (1994): International trade und restructuring in Eastern Europe, International Institute for Applied Systems Analysis, Laxenburg, Austria (en especial el capítulo 7, de Richter, S.: «Life without CMEA: foreign trade in Eastern and Central Europe», pp. 183-210).

GraZiani, G. (1982): Comecon, domination et dépendances, F. Maspero, París, 220 p.

- (1990): «L'impact des réformes économiques de l'URSS sur ses échanges avec le Tiers-Monde», en Sapir, J., dir.: L'URSS au tournant. Une économie en transition, L'Harmattan, París, pp. 162-183.

(1995): «La Unión Europea y su política comercial con Europa central oriental», Información Comercial Española, 738, pp. 35-51.

Hekimyan, V. (1996): «Échanges et coopération entre les Etats Unis et douze Etats issus de l'URSS: 1985-1995», Le Courrier des Pays de l'Est, 407, pp. 53-69. 
Instituto de Estudios DE EUROPA ORIEnTAL (1997): Economías de Europa del Este, 19891996. Balance provisional, Universidad Complutense, Madrid, $322 \mathrm{p}$.

IzRAELEWICZ, E. (1980): «Le Comecon: dépendances internes et pays socialistes dans l'échange international», en Lavigne, M., coord.: Stratégies des pays socialistes dans l'échange international, Economica, París, pp. 13-36.

LABARONNE, D. (1996 a): «Les relations commerciales des PECO avec l'Union Européenne et le Bassin Sud de la méditerranée», Le Courrier des Pays de l'Est, 410, pp. $15-26$.

- (1996 b): «Les échanges extérieurs des PECO avec les pays de la Communauté Européenne, de l'AELE et du Bassin Méditerranéen», Revue d'Études Comparatives Est-Ouest, vol. 27, núm. 1, pp. 5-37.

LAFAY, G. (1990): «La place de l'Europe de l'Est dans l'économie mondiale», en Andreff, W., dir.: Réforme et échanges extérieurs dans les pays de l'Est, l'Harmattan, París, pp. 111-122.

LANDAU, A. (1992): «L'AELE, la CEE et les pays de Europe centrale: vers una cohabitation?», Le Courrier des Pays de l'Est, 366, pp. 30-46.

Lavigne, M. (1979): Le Comecon, Cujas, París, 389 p.

coord. (1980): Stratégies des pays socialistes dans l'échange international, Economica, París, 331 p.

- (1985): Économie internationale des pays socialistes, Armand Colin, París, 254 p. - (1989): «Relaciones económicas Este-Oeste», Información Comercial Española, 674, pp. $13-36$.

- coord. (1990): L'URSS en transition: un nouveau marché, Centre Français du Commerce Extérieur, París, 231 p.

- (1997): Del socialismo al mercado. La difícil transición económica de la Europa del Este, Ediciones Encuentro, Madrid, 352 p.

LoBEJón, L. F. (1993): «La repercusión de las reformas adoptadas por los países de Europa Oriental sobre el comercio Este-Oeste», Cuadernos del Este, 9, pp. 11-23.

— (1995): «Apertura comercial y reforma económica en los países del Este», Información Comercial Española, 738, pp. 97-106.

Luengo, F. (1991): «Las relaciones económicas exteriores de los países del Este y la disolución del CAEM», Cuadernos del Este, 3, pp. 63-70.

- (1992): «La desintegración económica del bloque del Este: una reflexión sobre sus consecuencias», Boletín Económico ICE, 2339, pp. 2929-2936.

- (1992): «Las causas de la desintegración económica internacional del Este», Cuadernos del Este, 7, pp. 117-123.

- (1993): «La desintegración económica de Europa del Este», Cuadernos de Historia Contemporánea, 15, pp. 13-26.

- (1995): «El comercio exterior de los países del Este y el contexto económico internacional», Información Comercial Española, 738, pp. 7-16.

MARgOLIS, M. (1994): «L'Acord de libre-échange centre-européen: un projet d'integration non viable pour quatre économies en transition», Revue d'Études Comparatives Est-Ouest, 1, pp. 33-57.

MAтEJKA, H. (1994): «La dégradation des statistiques commerciales des PECO et son impact sur l'analyse des échanges», Le Courrier des Pays de l'Est, 392, pp. 3-10.

Muñoz, F., CendeJAS, J. L. y LoRCA, A. (1994): «Relaciones de dependencia en el proceso de integración económica. El caso de Polonia, Hungría y Checoslovaquia», Información Comercial Española, 728, pp. 109-130.

NAGEls, J. (1991): Du socialisme perverti au capitalisme sauvage, Editions de l'Université de Bruxelles, Bruselas, 305 p.

NU (1996): Estudio Económico y Social Mundial 1996, Naciones Unidas, Nueva York, 348 p. 
OCDE (1994): (Jbstacles aux échanges avec les économies en transition, OCDE, París, $50 \mathrm{p}$.

- (1994): lntégrer les économies de marché naissantes dans le système commercial international, OCDE, París, $113 \mathrm{p}$.

Palazullos, E. (1990): La economía soviética más allá de la Perestroika, Ediciones Ciencias Sociales, Madrid, $302 \mathrm{p}$.

- (1992): «Las repúblicas ex soviéticas: debilidades del sector exterior». Boletín Económico ICE, 2322, pp. 1336-1342.

— (1996): «Apertura e inserción exterior de la economía rusa» Boletín Económico ICE, 2525, pp. 17-31.

- (1996): Las economías postcomunistas de Europa del Este, Abacus Editorial, Madrid, $474 \mathrm{p}$.

- coord. (1993): La economía rusa en 1993 (consecuencias del primer año de reformas), Instituto de Europa Oriental, Universidad Complutense, Madrid, $345 \mathrm{p}$.

REY, V. (1996): Europes orientales, en Brunet, R.: Géographie Universelle, Belin-Reclus, Montpellier, pp. 8-206.

Rocher Vicedo, E. (1996): «La integración de Rusia en el nuevo orden económico mundial». V Jornadas de Economía Crítica, Santiago de Compostela, 17-18 de mayo de 1996, $22 \mathrm{pp}$.

Schiavone, G. (1983): Las instituciones del COMECON, Fondo de Cultura Económica, México, $255 \mathrm{p}$.

SEurot, F. (1987): Le commerce Est-Ouest, Economica, París, 174 p.

- (1989): Le système économique de l'URSS, PUF, París, 367 p.

Szamuely, L. (1993): «El proceso de apertura de las economías de Europa Oriental», Información Comercial Española, 717, pp. 143-154.

TIRASPOLSKY, A. (1989): «Le renouveau du commerce entre l'URSS, l'Europe de l'Est et la China», Le Courrier des Pays de l'Est, 337, pp. 43-52.

- (1989): «Le commerce extérieur de l'URSS en 1988: un début de réorientation», Le Courrier des Pays de l'Est, 339, pp. 29-36.

- (1990): «Radioscopia du commerce extérieur de l'URSS. Chiffres 1989 et nouvelles règles du jeu», Le Courrier des Pays de l'Est, 352, pp. 2-45.

- (1992): «Les échanges de l'ex URSS avec le monde extérieur en 1991-1992», Le Courrier des Pays de l'Est, 373, pp. 15-33.

- (1995): «Le commerce intra-CEI», Le Courrier des Pays de l'Est, 397-398, pp. 135-140.

VIDAL VILLA, J. M. ${ }^{a}$ (1990): Hacia una economía mundial. Norte-Sur frente a frente, Plaza y Janés, Barcelona, 409 p.

WILD, G. (1995): «CEI-Ouest: inertie et frémissements», Le Courrier des Pays de l'Est, 397398, pp. 152166

\section{ESTADÍSTICAS}

FOCUS: Boletín de información del GATT/Organización Mundial del Comercio, Ginebra. Varios años.

Fondo Monetario InTERnacional: Direction of trade statistic. Yearbook 1997, Washington, DC.

GATT/OMC: El comercio internacional. Tendencias y estadísticas. Ginebra. Varios años. NACIONES UNIDAS: Commodity trade statistics, New York. Varios años.

CEE/NACIONES Unidas: Étude sur la situation économique de l'Europe, New York. Varios años.

PlAN ECON REPORT: Developments in the economies of Eastern Europe and the former USSR, Washington, DC. Varios años. 
RESUMEN: Cambios en el comercio exterior de los paises del Este. La difícil reinserción en Europa. Los cambios políticos y económicos en Europa del Este, el desmantelamiento del CAEM, la desintegración de la URSS, y la distensión en las relaciones internacionales han modificado la dirección de los flujos comerciales de los países postcomunistas. Si durante los cuarenta años de vigencia del CAEM la región estuvo volcada hacia la URSS, en la actualidad el Este mira hacia el Oeste, en particular hacia la Unión Europea y más concretamente hacia Alemania. La composición de las importaciones y exportaciones revela la acusada dependencia de Europa central y oriental, primero de la Unión Soviética y en la actualidad de Alemania-UE. El éxito de las reformas emprendidas exige una mayor cooperación interregional.

PALABRAS ClAVE: comercio exterior, Europa del Este, acuerdos de asociación, obstáculos al comercio, integración regional.

ABSTRACT: Changes in the foreign trade of the countries of the East. The difficult as similation into Europe. The direction of the trading lines of the post-communist countries has been modified by the political and economical changes of the countries of the East of Europe, the dismantling of the COMECON, as well as by the disintegration of the USSR and the detente in the international relationships. During the forty years that the COMECON was prevailing, that region centred its attention on the USSR, but nowadays the East loolks at the West, concretaly at the European Union and more exactly at Germany. The composition of the imports and exports reveals the marked dependence on Central and Eastern Europe, first on the Soviet Union and nowadays on Germany-EU. The success of the reforms that were undertaken demands a higher interregional co-operation.

KEY WORDS: foreign trade, Eastern Europe, association agreements, difficulties in trading, regional assimilation.

RÉSUMÉ: Changements dans le comerce extérieur des pays de l'Est. La difficile incorporation en Europe. Les changements politiques et économiques de l'Europe de l'Est, le démantèlement du CAEM, la désintégration de l'URSS, et la distension des relations internationales ont modifié la direction des flux commerciaux des pays postcommunistes. Si pendant les quarante ans d'existence du CAEM la région se tournait vers l'URSS, actuellement l'Est regarde vers l'Ouest, en particulier vers l'Union Europénne et plus concrètement vers l'Allemagne. La composition des importations et exportations montre la forte dépendance d'Europe centrale et orientale, d'abord de l'Union soviétique et actuellement de l'Allemagne-UE. Le succès des réformes entreprises exige une plus importante coopération interrégionale.

Mots CLÉs: commerce extérieur, Europe de l'Est, accords d'association, obstacles au commerce, integration régionale. 